University of Louisville

ThinkIR: The University of Louisville's Institutional Repository

Electronic Theses and Dissertations

$12-2012$

\title{
Hyperhomocysteinemia alters sinoatrial and atrioventricular nodal function : role of the cardiac NMDA receptor.
}

Chirag V. Soni

University of Louisville

Follow this and additional works at: https://ir.library.louisville.edu/etd

\section{Recommended Citation}

Soni, Chirag V., "Hyperhomocysteinemia alters sinoatrial and atrioventricular nodal function : role of the cardiac NMDA receptor." (2012). Electronic Theses and Dissertations. Paper 1360.

https://doi.org/10.18297/etd/1360

This Doctoral Dissertation is brought to you for free and open access by ThinkIR: The University of Louisville's Institutional Repository. It has been accepted for inclusion in Electronic Theses and Dissertations by an authorized administrator of ThinkIR: The University of Louisville's Institutional Repository. This title appears here courtesy of the author, who has retained all other copyrights. For more information, please contact thinkir@louisville.edu. 


\title{
HYPERHOMOCYSTEINEMIA Alters SinOATRIAL AND ATRIOVENTRICULAR NODAl Function: Role OF THE CARdiac NMDA RECEPTOR
}

\author{
By \\ Chirag V. Soni \\ B.A., Northwestern University, 1999 \\ M.S., University of Louisville, 2005 \\ A Dissertation \\ Submitted to the Faculty of the \\ School of Medicine of the University of Louisville \\ In Partial Fulfillment of the Requirements \\ For the Degree of \\ Doctor of Philosophy \\ Department of Physiology and Biophysics \\ University of Louisville \\ Louisville, KY
}

December 2012 
Copyright 2012 by Chirag V. Soni

All rights reserved 


\title{
HYPERHOMOCYSTEINEMIA ALTERS SINOATRIAL AND ATRIOVENTRICULAR NODAL FUNCTION: ROLE OF THE CARDIAC NMDA RECEPTOR
}

By

\author{
Chirag V. Soni
}

B.A., Northwestern University, 1999

M.S., University of Louisville, 2005

A Dissertation Approved on

August $27^{\text {th }}, 2012$

By the Following Dissertation Committee:

Claudio Maldonado, Ph.D., Mentor

Suresh Tyagi, Ph.D.

Irving Joshua, Ph.D.

William Wead, Ph.D.

Aruni Bhatnagar, Ph.D. 


\section{DEDICATION}

This dissertation is dedicated to my late grandfather Shantilal Soni, my grandmother Shardaba Soni, my grandfather Pujalal Soni, my grandmother Susilaba Soni and my foi Kantaben Soni.

Foremost, this dissertation is dedicated to my loving parents Dr. Vinod and Geeta Soni, who worked very hard to be able to provide opportunities for their children which they did not have growing up in rural India, my sisters Hina and Amita who always keep me in line, and my baby niece Ava, the light of my life. 


\section{ACKNOWLEDGEMENTS}

I would like to acknowledge and thank everyone who contributed to this work, without whom this would not have been possible.

First and foremost, I would like to acknowledge and thank my mentor, Dr. Claudio Maldonado. His unwavering and unceasing support, patience, guidance, and sacrifices made this work possible. Most importantly, he never gave up on me. He is the exemplar of what distinguishes an outstanding and dedicated mentor.

I would like to thank my committee members, Dr. Irving Joshua, Dr. William Wead, Dr. Suresh Tyagi, and Dr. Aruni Bhatnagar for all their help and guidance. I would like to thank the faculty and staff of the Department of Physiology and Biophysics. I would especially like to acknowledge Drs. Joshua and Wead for their invaluable support and guidance.

I would like to thank Dr. Tyagi and Dr. Bhatnagar for allowing me to work in their laboratories, and I would like to thank everyone in both labs for all their help. I would especially like to acknowledge Dr. Sathnur Pushpakumar, Dr. Gustavo PerezAbadia, Dr. Nathaniel Todnem, Dr. Srikanth Givvimani, Dr. Naira Metrevelli, and Dr. Phanikumar Patibandla for all their contributions to this work. Additionally I would like to thank Dr. Srinivas Tipparaju and Peter Kilfoil for teaching me about whole-cell and patch-clamp electrophysiology.

Finally, I would like to thank the members of the Pathology Core, as well as Dr. Rong Wan for assistance with immunohistochemistry. 


\section{AbSTRACT \\ HYPERHOMOCYSTEINEMIA ALTERS SinOATRIAL AND ATRIOVENTRICULAR NODAL FunCTION: ROLE OF THE CARDIAC NMDA RECEPTOR \\ Chirag V. Soni}

August 27, 2012

Introduction: Hyperhomocysteinemia (HHcy) is a pathological condition characterized by excessive levels of plasma homocysteine (Hcy). Patients with HHcy are reported to be at risk for arrhythmias like atrial fibrillation and sudden cardiac death (SCD); however, the causative mechanisms remain unknown. The effects of HHcy on sinus node function, atrioventricular conduction and ventricular vulnerability were investigated by in vivo electrophysiological (EP) analysis, and the role of the cardiac $N$-methyl-D-aspartate receptor (NMDA-R) in promoting Hcy-induced conduction abnormalities was explored.

Materials and Methods: Anesthetized wild-type control mice (WT), mice receiving Hcy in the drinking water for 12 weeks $(D W)$, and heterozygous cystathionine- $\beta$-synthase knockout mice $\left(C B S^{+/}\right)$were subjected to electrocardiographic (ECG) analysis and programmed electrophysiological (EP) studies. To examine the role of the NMDA-R in eliciting conduction changes in HHcy, animals from the three groups were subjected to paired-design repeat EP studies before and after intraperitoneal injection of magnesium sulfate $\left(\mathrm{MgSO}_{4}, 20 \mathrm{mg} / \mathrm{kg}\right)$, an endogenous blocker of NMDA-R. Another set of studies 
utilized a specific NMDA-receptor antagonist, dizocilpine (MK-801), in similarly paireddesign studies in an acute, intraperitoneal infusion model of HHcy. Expression levels of cardic NMDA-R in all three groups of animals were quantified by immunoblotting, and immunohistochemical identification of cardiac NMDA-Rs at the mouse atrioventricular (AV) junction was undertaken.

Results: $D W$ compared to $W T$ had significantly shorter RR, PR, QT, and HV intervals, corrected sinus node recovery times (CSNRT), Wenckebach periodicity (WP), AV nodal effective refractory periods (AVNERP), and right ventricular effective refractory periods (RVERP). No ventricular arrhythmias were induced in either $W T$ or $D W$. In the paireddesign studies, blockade of cardiac NMDA-R with $\mathrm{MgSO}_{4}$ had no effect on any ECG or EP variables in WT but significantly prolonged RR, QT, HV, CSNRT, WP, and AVNERP in $D W$ and $C B S^{+/}$animals. Immunopositive staining for cardiac NMDA-R at the mouse AV junction was detected.

Conclusions: Significant changes in conduction were observed between wild-type mice and mice with diet-induced or genetically-induced hyperhomocysteinemia (HHcy). Lowdose magnesium administration did not alter ECG or EP conduction variables in wildtype mice, but had a profound effect on mice with HHcy. These results suggest that shortened sinoatrial and atrioventricular conduction time in mild HHcy may involve cardiac NMDA-Rs. 


\section{TABLE OF Contents}

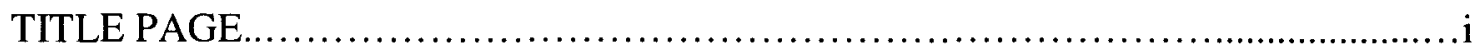

SIGNATURE PAGE....................................................................................i

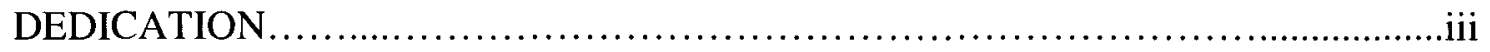

ACKNOWLEDGMENTS .....................................................

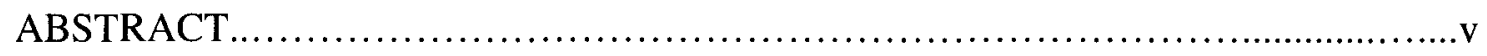

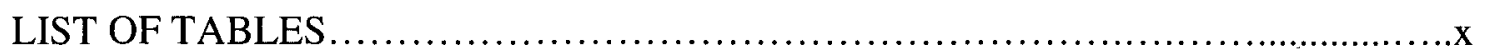

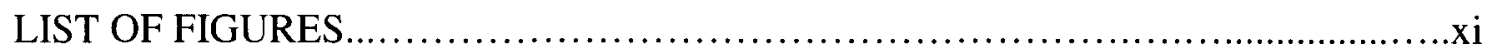

\section{CHAPTER I: INTRODUCTION AND BACKGROUND}

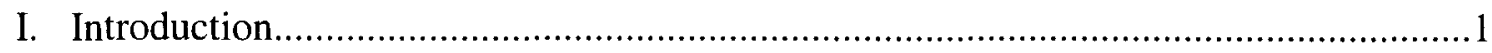

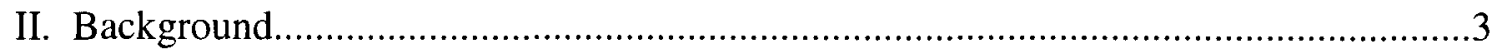

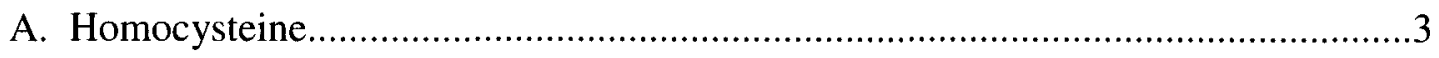

B. Accumulation of homocysteine .............................................................4

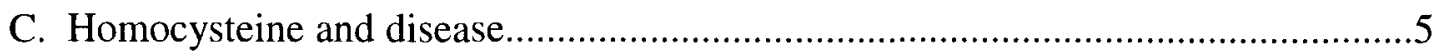

D. Cardiac arrhythmias in hyperhomocysteinemia........................................6

E. Cardiac action potentials.....................................................................

F. Glutamate receptors and the NMDA receptor............................................ 8

G. Homocysteine and oxidative stress....................................................... 10

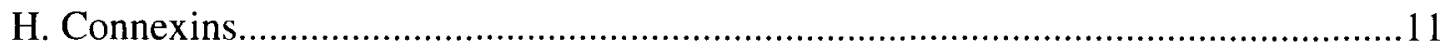

I. Cardiac remodelling and connexin dysfunction.....................................13 
J. Remodelling at the sinoatrial and atrioventricular nodes

\section{CHAPTER II: HYPOTHESIS AND SPECIFIC AIMS}

A. Hypothesis and Specific Aims

20

CHAPTER III: AIM 1: HYPERHOMOCYSTEINEMIA ALTERS SINOATRIAL AND ATRIOVENTRICULAR CONDUCTION

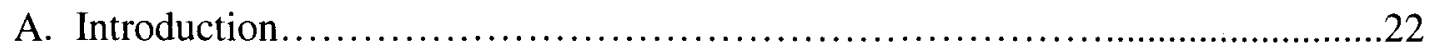

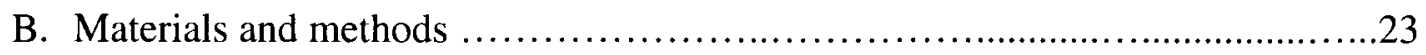

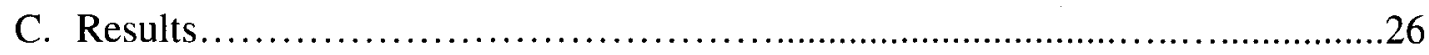

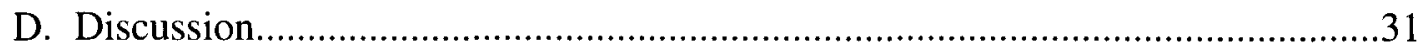

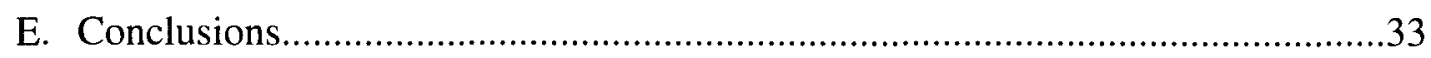

CHAPTER IV: AIM 2: HYPERHOMOCYSTEINEMIA-INDUCED CONDUCTION ABNORMALITIES ARE ASSOCIATED WITH CARDIAC NMDA RECEPTOR

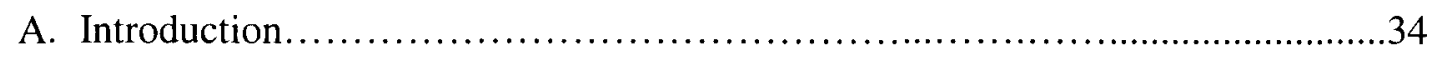

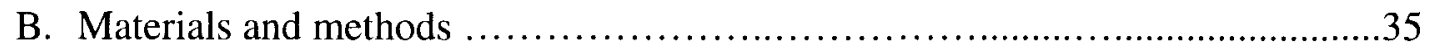

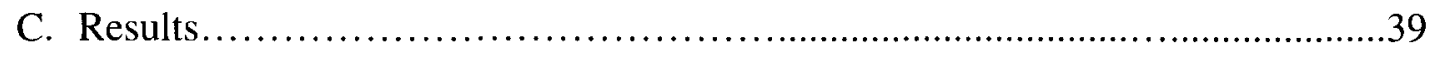

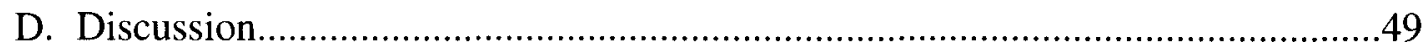




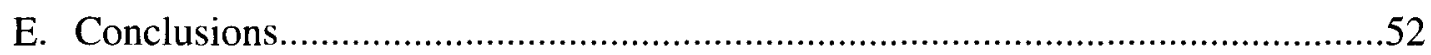

CHAPTER V: AIM 3: CARDIAC NMDA RECEPTOR EXPRESSION IN MILD HYPERHOMOCYSTEINEMIA

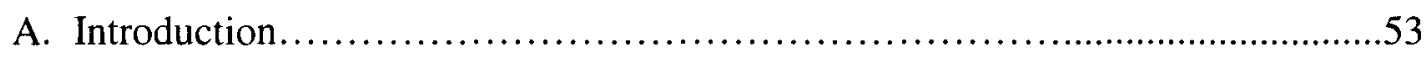

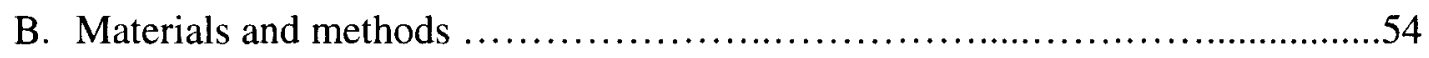

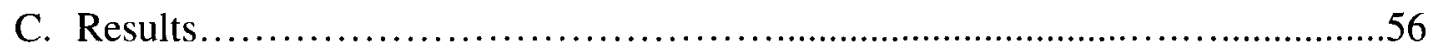

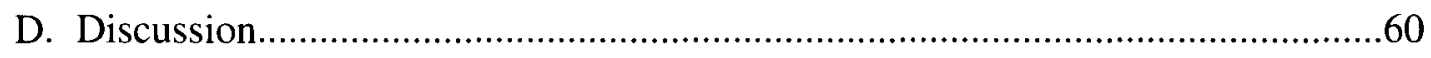

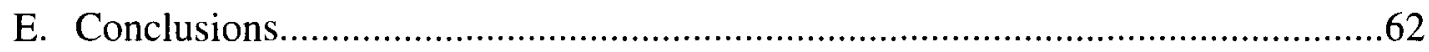

CHAPTER VI: SUMMARY AND FUTURE DIRECTIONS

A. Summary and Future Directions..

REFERENCES.

CURRICULUM VITAE. 


\section{LIST OF TABLES}

TABLE PAGE

1. Comparison of Surface ECG and Intracardiac Electrograms.............................26

2. Comparison of Atrial and Ventricular Programmed Stimulation Studies...................28 


\section{LIST OF FIGURES}

$\begin{array}{ll}\text { FIGURE } & \text { PAGE }\end{array}$

1. Representative surface ECGs and intracardiac His bundle electrograms...................27

2. PR Interval and Wenckebach Periodicity..................................................... 38

3. 2:1 AV block and AV nodal effective refractory period.....................................39

4. PR Interval and Wenckebach Periodicity................................................40

5. 2:1 AV block and AV nodal effective refractory period....................................41

6. Surface ECG variables before and after administration of $\mathrm{MgSO}_{4} \ldots \ldots \ldots \ldots \ldots \ldots \ldots \ldots . . \ldots 3$

7. Surface ECG variables before and after administration of $\mathrm{MgSO}_{4} \ldots \ldots \ldots \ldots \ldots \ldots \ldots . . . . . . . . . . . .44$

8. Surface ECG variables before and after administration of $\mathrm{MgSO}_{4} \ldots \ldots \ldots \ldots \ldots \ldots \ldots \ldots . . \ldots . \ldots \ldots$

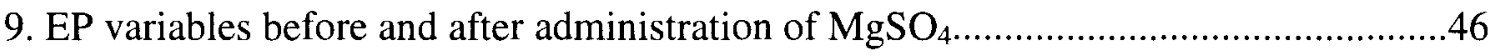

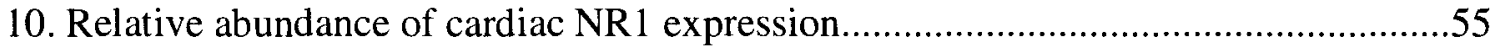

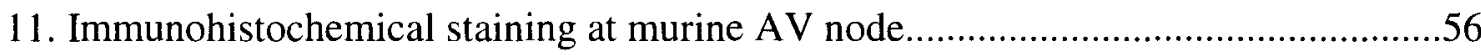

12. Immunohistochemical staining at murine AV node.............................................57 


\section{Chapter I}

\section{INTRODUCTION}

Increased plasma homocysteine (Hcy) is an independent risk factor for a significant number of cardiovascular diseases, including hypertension, coronary artery disease, atherosclerosis, and heart failure. Recent reports demonstrate a link between hyperhomocysteinemia (HHcy) and arrhythmogenesis leading to atrial fibrillation (AF) as well as lethal arrhythmias leading to sudden cardiac death (SCD). The exact mechanism by which higher levels of Hcy may facilitate induction of arrhythmias has not been elucidated.

Hcy is known to activate the N-methyl-D-aspartate receptor (NMDA-R) in the brain, increasing intracellular calcium $\left[\mathrm{Ca}^{2+}\right]_{\mathrm{i}}$ and the excitability of cells ${ }^{1}$. The NMDA$\mathrm{R}$ is expressed in several peripheral tissues, including the heart, kidney, lungs, testes, GI tract $^{2}$ as well as in the vascular endothelium ${ }^{3}$ and smooth muscle ${ }^{4}$. In the heart it has been identified in both the myocardium as well as in the specialized conductive tissues ${ }^{5,6}$. Although subunits of NMDA-R are expressed in various cardiac cells, the role of cardiac NMDA-Rs in normal or pathological cardiac conduction is unknown.

Additionally, HHcy induces mitochondrial oxidative stress of cardiomyocytes, increasing levels of reactive oxygen species (ROS) which activate matrix metalloproteinases (MMPs) involved in extracellular matrix (ECM) remodelling ${ }^{7,8}$. 
MMP-mediated remodelling is a ubiquitous phenomenon that results in the degradation and recycling of membrane-associated proteins, including ion channels like the $\mathrm{N}$ methyl-D-aspartate receptor (NMDA-R), and connexins (Cxs) which mediate intercellular communication via formation of gap junction channels (GJCs). Changes in NMDA-R subunit composition and receptor density can alter cell-to-cell signal propagation in the myocardium and the specialized conduction system (SCS) of the heart. Communication between cells at the sinoatrial node (SAN), internodal pathways, atrioventricular node (AVN) and His-Purkinje fibers could be altered by MMP-mediated remodelling in patients with HHcy. Changes in NMDA receptor subunit expression can have a profound effect on normal impulse propagation, but more importantly on signal conduction between atria and ventricles across the AVN.

The overall hypothesis of this dissertation was arrhythmogenesis may arise in HHcy due to higher circulating levels of Hcy, which acts as an agonist at the cardiac NMDA receptor. This hypothesis was tested by 1 ) measuring electrocardiographic (ECG) and electrophysiological (EP) variables in order to compare cardiac conduction in wildtype and hyperhomocysteinemic mice, 2) characterizing the role of cardiac NMDA-R in the conduction changes observed in HHcy by utilizing pharmacological inhibition of the receptor, and 3) comparing cardiac NMDA receptor expression levels in wild-type and HHcy mice. In this dissertation, evidence that supports potential mechanisms by which increased plasma Hcy may increase nodal cell excitability, and thereby facilitate the initiation of arrhythmias, is presented. 


\section{BACKGROUND}

\section{Homocysteine}

Homocysteine (Hcy) is a non-proteinogenic, sulfur-containing excitatory amino acid. It is similar to cysteine, another thiolated amino acid which is formed using Hcy as a precursor, except that Hcy contains one more methylene group $\left(\mathrm{CH}_{2}\right)$. It is generated as a consequence of methionine metabolism, and is involved in the transmethylation and trans-sulfuration pathways. In the transmethylation pathway, methionine, which is orally consumed as protein, becomes adenosylated via transfer of adenosine from ATP by methionine adenosyltransferase. This forms S-adenosylmethionine (SAM) which is a universal methyl group $\left(-\mathrm{CH}_{3}\right)$ donor. Methyl transferases, such as those which catalyze the methylation of DNA and RNA, transfer the methyl group bonded to the sulfur atom in SAM to its target. Phenylethanolamine-N-methyltransferase (PNMT) uses SAM to donate a methyl group to norepinephrine to produce epinephrine. Once SAM is demethylated, it becomes S-adenosylhomocysteine (SAH). SAH is hydrolyzed by SAH hydrolase to yield homocysteine.

Hcy at this point can continue in the transmethylation pathway and be remethylated to methionine, or it can be further metabolized by the trans-sulfuration pathway. In the transmethylation pathway, methionine can be regenerated from homocysteine by methionine synthase (MS), which is another methyltransferase. 5methyltetrahydrofolate, which is formed following the vitamin $\mathrm{B}_{12}$-dependent reduction of 5,10-methylenetetrahydrofolate by methylenetetrahydrofolate reductase (MTHFR), is used as a methyl donor by MS to re-methylate Hcy and regenerate methionine. In the 
trans-sulfuration pathway, Hcy condenses with serine to form cystathionine via a vitamin $\mathrm{B}_{6}$-dependent reaction catalyzed by cystathionine- $\beta$-synthase (CBS). Cystathionine is cleaved to create cysteine and $\alpha$-ketobutyrate by cystathionine- $\gamma$-lyase (CGL), which is also vitamin $\mathbf{B}_{6}$-dependent. Cysteine can be further metabolized by the trans-sulfuration pathway to form glutathione, an important cellular antioxidant.

\section{Accumulation of Hcy}

Elevated plasma and tissue accumulation of Hcy can arise in several ways. As previously described, Hcy is generated as methionine is converted to SAM/SAH. Increased dietary intake of methionine can therefore lead to higher levels of Hcy. Also, increased activity of methyl transferases will yield more SAH, and therefore more Hcy, following methylation reactions. In addition, genetic polymorphisms have been identified in several of the enzymes involved in the transmethylation and trans-sulfuration pathways. Genetic polymorphisms in MTHFR, CBS, MS, and MS reductase have been identified, and several of these are associated with varying degrees of hyperhomocysteinemia or homocystinuria, an inherited disorder affecting the metabolism of sulfur-containing amino acids ${ }^{9}$. One of the most extensively studied MTHFR polymorphisms, the substitution of $\mathrm{C} \rightarrow \mathrm{T}$ at nucleotide position 677 (C677T) which results in the substitution of valine for alanine, causes enzyme deficiency wherein homozygous individuals have MTHFR enzyme activity reduced to $30 \%$ of wild-type activity $^{10}$. Over 100 different mutations have been identified in the CBS gene, and many have been linked to varying degrees of hyperhomocysteinemia ${ }^{11}$. The classical genetic disease homocystinuria, caused by a CBS deficiency, results in extremely high levels of 
plasma and urinary homocysteine and methionine. Homocystinurics present with mental retardation, musculoskeletal deformities, motor and gait dysfunction, and ectopia lentis 9 B vitamin deficiency can also cause elevated levels of Hcy, since several of the enzymes involved in Hcy metabolism require B vitamins as cofactors (MTHFR requires $B_{12}$, CBS and CGL both require $\left.B_{6}\right)$. Folate $\left(B_{9}\right)$ is also required - the tetrahydrofolate cycle provides the methyl group required to regenerate methionine from Hcy. Without proper intake of B vitamins these processes will be hindered, resulting in increased plasma Hcy. Indeed, B vitamin supplementation is shown to decrease plasma Hcy.

Renal dysfunction can also lead to HHcy. Plasma Hcy levels are determined by intracellular metabolism of Hcy, import/export of Hcy between the plasma and the various tissues most largely associated with Hcy metabolism ${ }^{12}$, and renal clearance of Hcy. Renal clearance of Hcy is hindered in patients with renal disease/dysfunction, resulting in the accumulation of Hcy in the plasma.

Normal fasting plasma Hcy values generally fall within 5-10 $\mu \mathrm{M}$. Values greater than $10 \mu \mathrm{M}(10-30 \mu \mathrm{M})$ are considered mildly hyperhomocysteinemic. Moderate HHcy is characterized by plasma Hcy values between $30-100 \mu \mathrm{M}$, and severe HHcy is characterized by plasma Hcy levels above $100 \mu \mathrm{M}$.

\section{Hcy and Disease}

Kilmer S. McCully first postulated the homocysteine theory of arteriosclerosis in $1975^{13}$. It is now well-established that increased plasma Hcy is a risk factor for cardiovascular, cerebrovascular, and neurodegenerative disease. High plasma Hcy levels have been linked to coronary artery disease, hypertension, acute myocardial infarction, 
stroke, atherosclerosis, heart failure, atrial fibrillation, and sudden cardiac death (SCD) ${ }^{9}$, ${ }^{14-23}$. Increased plasma Hcy is also a risk factor for neurologic disorders like Alzheimer's and Parkinson's diseases, as well as psychiatric disorders like schizophrenia.

\section{Cardiac Arrhythmias in HHcy}

The risk factors for arrhythmogenesis are multifactorial. HHcy is associated with hypertension, coronary artery disease, and cardiac interstitial fibrosis ${ }^{24}$. The presence of one or a combination of these risk factors induces structural derangements to the ventricular myocardium, thereby increasing the chance of creating substrate for the induction of ventricular tachycardia (VT) and possibly ventricular fibrillation (VFib). In the absence of intervention, VT degenerates into VFib and sudden cardiac death (SCD). Several studies associate elevated Hcy with $\mathrm{SCD}^{9,14,16}$.

Additionally, several studies assert an association between HHcy and atrial fibrillation ${ }^{25}$, especially in the context of the thrombogenic potential of increased plasma Hcy and the consequent risk of stroke $\mathrm{e}^{22,23}$. Atrial fibrillation arises due to extensive structural and electrical atrial remodelling. HHcy-induced MMP activation plays a role in the structural and electrical remodelling of the atria ${ }^{26,27}$. Following orthotopic heart transplantation, HHcy is associated with altered atrial electrical conduction manifesting as $\mathrm{P}$ wave dispersion ${ }^{28}$. Hcy also modulates sodium and potassium currents in human atrial myocytes ${ }^{29,30}$, highlighting another plausible mechanism by which elevated Hcy may initiate atrial arrhythmias. 


\section{Cardiac Action Potentials}

The basis for cardiac impulse generation and conduction is cardiac cell excitability and spatiotemporal ionic permeability changes. Ionic conductances through specific types of $\mathrm{Na}^{+}, \mathrm{K}^{+}$, and $\mathrm{Ca}^{2+}$ channels underlie the different phases of the cardiac action potential, as well as the different morphologies of action potentials elicited by the various cardiac tissues.

The cardiomyocyte action potential typically has four phases: in Phase 4 the cell is at rest, rapid depolarization occurs during Phase 0 , early repolarization begins during Phase 1, delayed repolarization and a slow inward calcium current underlie the plateau of Phase 2, and repolarization is completed during Phase 3. Not all cardiac action potentials exhibit all four phases. Nodal cells of the specialized conduction system only exhibit three phases: an unstable Phase 4, Phase 0 depolarization, and Phase 3 repolarization. The unstable Phase 4 of nodal cells is responsible for cardiac automaticity.

In working myocytes, an inward sodium current $\left(\mathrm{I}_{\mathrm{Na}}\right)$ activated by opening of $\mathrm{Na}_{\mathrm{v}} 1.5(S C N 5 A)$ voltage-gated sodium channels causes the rapid phase 0 depolarization. The phase 1 repolarization is mediated by a transient outward $\mathrm{K}^{+}$current $\left(\mathrm{I}_{\mathrm{to}}\right)$ mainly through $\mathrm{K}_{\mathrm{v}} 4.3\left(K C N D 3\right.$ ) assembled voltage-gated $\mathrm{K}^{+}$channels. The plateau in phase 2 is due to opening of L-type voltage-gated calcium channels $\left(\mathrm{Ca}_{\mathrm{v}} 1.2\right)$, giving rise to inward conductance $\mathrm{I}_{\mathrm{Ca}, \mathrm{L}}$. Repolarization is mediated by three outward delayed-rectifier $\mathrm{K}^{+}$ channels: at the beginning of phase 2 , the ultra-rapidly activating delayed-rectifier $\mathrm{K}^{+}$ channel $\left(\mathrm{K}_{\mathrm{v}} 1.5 / 3.1\right)$ permits outward current $\mathrm{I}_{\mathrm{Kur}}$; midway through phase 2 the slowly activating delayed-rectifier $\mathrm{K}^{+}$channel $\left(\mathrm{K}_{\mathrm{v}} \mathrm{LQT} 1\right)$ opens to conduct $\mathrm{I}_{\mathrm{Ks}}$; finally, late 
repolarization in phase 3 is mediated by the rapidly activating delayed-rectifier $\mathrm{K}^{+}$ channel (hERG), which conducts $\mathrm{I}_{\mathrm{Kr}}$.

An important difference between nodal cells and cells of the working myocardium is that nodal cells of the proximal conduction system lack the fast, voltagegated $\mathrm{Na}^{+}$channel $\left(\mathrm{Na}_{v} 1.5\right)$ responsible for rapid phase 0 depolarization in working myocytes. The Purkinje fibers of the distal conduction system, however, do express the fast $\mathrm{Na}^{+}$channels; this allows the Purkinje network to rapidly convey action potentials to the ventricular endocardium and epicardium. Phase 0 depolarization in nodal cells is mediated by activation of T-type voltage-gated calcium channels $\left(\mathrm{Ca}_{\mathrm{v}} 3.1, \mathrm{I}_{\mathrm{Ca}, \mathrm{T}}\right)$ as well as the L-type channels found in non-pacemaker cells. Additionally, nodal cells express channels which give rise to the "funny" current $\mathrm{I}_{\mathrm{f}}$, also known as the pacemaker current. Hyperpolarization-activated, cyclic nucleotide-gated $(\mathrm{HCN})$ channels at the sinoatrial node are responsible for the unstable phase 4 which confers automaticity. HCN channels are expressed at the AV node as well as in Purkinje fibers.

There are other currents which play a role in shaping the cardiac action potential, namely other $\mathrm{K}^{+}$currents such as the ATP-gated $\mathrm{I}_{\mathrm{KATP}}$, acetylcholine-gated $\mathrm{I}_{\mathrm{KAch}}$, and voltage-gated inward-rectifying $I_{K 1}$ currents.

\section{Glutamate Receptors--The NMDA Receptor}

Although they have been most extensively studied in the brain, glutamate receptors (GluRs) are present in many tissues outside the nervous system, including the heart ${ }^{6,31}$. GluRs are activated by the excitatory amino acid L-glutamate and are divided into 2 subtypes: metabotropic glutamate receptors (mGluRs) and ionotropic glutamate 
receptors (iGluRs). Both types, when activated, result in an increase in intracellular $\mathrm{Ca}^{2+}$ by different mechanisms. Metabotropic GluRs are G-protein-coupled receptors; binding of glutamate to mGluRs initiates signal transduction events such as activation of phospholipase $\mathrm{C}$, which hydrolyzes phosphatidylinositol-4,5-bisphosphate $\left(\mathrm{PIP}_{2}\right)$ into inositol 1,4,5-trisphosphate $\left(\mathrm{IP}_{3}\right)$ and diacylglycerol (DAG). Subsequently, $\mathrm{IP}_{3}$ activates the release of intracellular $\mathrm{Ca}^{2+}$ from stores within the sarcoplasmic reticulum. Acidic derivatives of Hcy, like homocysteic acid (HcyA), activate mGluRs in neuronal and nonneuronal tissues ${ }^{32}$, initiating G-protein mediated signalling and causing an increase in $\left[\mathrm{Ca}^{2+}\right]_{\mathrm{i}}$. mGluRs have also been identified in mammalian heart ${ }^{33}$.

Ionotropic GluRs are present in various mammalian tissues as well ${ }^{31,34}$. There are 3 classes of iGluRs, each named after its highest affinity agonist: N-methyl-D-aspartate (NMDA) receptors, alpha-amino-3-hydroxy-5-methyl-4-isoxazole propionic acid (AMPA) receptors (also known as quisqualate receptors), and kainate (Ka) receptors. Activation of iGluRs predominantly induces $\mathrm{Ca}^{2+}$ influx, besides permitting $\mathrm{Na}^{+}$influx and $\mathrm{K}^{+}$efflux, causing depolarization and excitation of the cells. The NMDA receptor is unique in that its activation is both ligand- and voltage-dependent. Both glutamate and the co-agonist glycine are required to bind, and a voltage-dependent $\mathrm{Mg}^{2+}$ block occluding the central pore must be relieved by local membrane depolarization before the channel becomes permeable to $\mathrm{Ca}^{2+}, \mathrm{Na}^{2+}$, and $\mathrm{K}^{+}$.

Most NMDA receptors are assembled from NR1 subunits (of which there are eight alternative splice variants) and NR2 subunits (of which there are 4 isoforms, NR2AD). NR3 subunits have also been identified, which confer an inhibitory effect on the receptor. NR1 and NR2 subunits contain binding sites for glycine and glutamate, 
respectively. Hcy activates the NMDA-R in neurons ${ }^{1}$, endothelial cells ${ }^{3}$, and vascular smooth muscle cells ${ }^{4}$. Hcy is capable of binding to both the glycine and glutamate binding sites of NMDA-R. Interestingly, Hcy acts as an agonist at the glutamate binding site on NR2, but acts as a partial antagonist at the glycine binding site on NR $1^{1}$. Glycine elevated above physiological levels therefore increases the agonistic effects of Hcy.

Supporting evidence that excitatory amino acids acting on the NMDA-R play a role in arrhythmogenesis is a study demonstrating that blockade of the receptor decreases ischemia/reperfusion-induced arrhythmias but not ischemia-induced arrhythmias ${ }^{35}$. These findings suggest that circulating factors are involved in arrhythmia induction; also in the setting of myocardial ischemia/reperfusion, blocking the NMDA-R is important in reducing arrhythmogenic substrate. In this context, exposure to high levels of Hcy or other circulating excitatory amino acids may overactivate the cardiac NMDA-R, increasing $\left[\mathrm{Ca}^{2+}\right]_{\mathrm{i}}$ and altering the rate of cell-to-cell conduction, thereby creating arrhythmogenic substrate.

\section{Hcy and Oxidative Stress}

Increased plasma Hcy induces oxidative stress by activating inducible nitric oxide

synthase (iNOS) and NADPH oxidase ${ }^{7,36-38}$. Both contribute to the formation of reactive oxygen species (ROS) and reactive nitrogen species (RNS) like peroxide $\left(\mathrm{H}_{2} \mathrm{O}_{2}\right)$, superoxide $\left(\mathrm{O}_{2}{ }^{-}\right)$, hydroxyl radical $(\mathrm{OH})$, and peroxynitrite ${ }^{7}$. Increased levels of myocardial iNOS are associated with arrhythmogenesis and $\mathrm{SCD}^{39}$. HHcy increases mitochondrial oxidative stress of cardiomyocytes, increasing levels of ROS which activate matrix metalloproteinases (MMPs) involved in extracellular matrix (ECM) 
remodelling ${ }^{8}$. Hcy also diminishes activity of superoxide dismutase (SOD) and many redoxins which reduce ROS, further exacerbating oxidative stress ${ }^{7}$.

It is established that Hcy activates MMPs by oxidizing inhibitors of MMPs, such as tissue and cardiac inhibitors of MMPs (TIMPs and CIMPs, respectively). Latent MMPs associate with nitric oxide (NO) and TIMPs in a ternary complex; ROS and RNS generate nitrosylated tyrosine residues in TIMPs, thereby liberating active MMPs ${ }^{7,40}$. Overactivation of MMPs is responsible for abnormal myocardial remodelling, which results in increased interstitial collagen associated with fibrosis ${ }^{24}$. In paradigms where cardiac remodelling associated with fibrosis occurs (e.g. heart failure, myocardial infarction or atrial fibrillation), an increased likelihood of re-entrant arrhythmias is a common feature. Conduction abnormalities observed in infarction and cardiac failure appear to be related to connexin dysfunction and increased action potential duration (APD), whereas in atrial fibrillation, reduction of APD appears to play a major role ${ }^{41}$.

\section{Connexins}

Intercellular communication between cardiomyocytes, nodal cells, and endothelial cells is important in the coordinated excitation and contraction of the working myocardium, as well as in impulse propagation through the SCS of the heart. Intercellular communication is mediated by gap junction channels (GJCs) composed of connexins (Cxs). Six connexins join to form a connexon (a hemichannel assembly comprising half of a GJC) which communicates with a hemichannel from an adjacent cell to form a functional GJC between the two cells. The selective permeability, unitary conductance of ions, and gating characteristics of an assembled GJC is determined by the $\mathrm{Cx}$ isotype 
composition of the channels. Twenty-one human $\mathrm{Cx}$ isoforms have been identified, with five present in the heart: $\mathrm{Cx} 31.9, \mathrm{Cx} 37, \mathrm{Cx} 40, \mathrm{Cx} 43$, and $\mathrm{Cx} 45^{41-48}$. The latter three have been extensively studied in the heart. Cx43 is the most abundantly expressed Cx in the heart; it is present in the atrial and ventricular working myocardium, as well as the distal $\operatorname{SCS}^{41,42}$. GJCs composed entirely of Cx43 allow a unitary conductance of 115-120 picoSiemens $(\mathrm{pS})^{49,50} . \mathrm{CX} 40$ is present in and around the AVN, as well as in the atrial myocardium ${ }^{41}$. Channels composed of $\mathrm{Cx} 40$ allow faster conductance at $180-200 \mathrm{pS}^{50}$, 51. Cx45 is found in the SAN, AVN, and the internodal conduction system ${ }^{52} \cdot \mathrm{Cx} 45$ channels exhibit slower unitary conductance, at $35 \mathrm{pS}^{53}$. A recently discovered connexin isoform $\mathrm{Cx} 31.9$ in humans (Cx30.2 in mouse) is thought to play a role in slowing the impulse conduction across the AVN ${ }^{54,55}$. Cx31.9 is predominantly localized to the SAN and AVN, and allows the slowest conductance, at $9 \mathrm{pS}^{50,54,55}$.

Assembly of Cxs into hemichannels, and ultimately into GJCs, can result in 1 of 3 types of channels. Homotypic channels are composed of the same Cx isotypes in both hemichannels. Heterotypic channels are formed by hemichannels assembled from 1 isotype apposed to hemichannels composed entirely of a different $\mathrm{Cx}$ isotype. Heteromeric channels are the most variable; each hemichannel can have a variable $\mathrm{Cx}$ isotype configuration. If you consider only 2 of the 21 identified $\mathrm{Cx}$ isoforms, which can be assembled into any configuration of hemichannels and GJCs, there would be at least 196 different channel configurations ${ }^{56}$. Due to the several possible configurations of heterotypic and heteromeric channels, the permeability, conductance, and gating properties of each channel varies as the summation of the properties of individual $\mathrm{Cx}$ subunits. In HHcy, activation of MMPs induces MMP-mediated cardiac remodelling ${ }^{24}$, 
and as observed in heart failure and myocardial infarction ${ }^{57-62}$, remodelling alters the expression, distribution, and regulation of Cxs, ultimately modifying electrical continuity between cardiac cells.

\section{Cardiac Remodelling and Cx Dysfunction}

Cardiac remodelling in patients with heart failure is associated with various types of arrhythmias and conduction abnormalities ${ }^{63}$. A common finding in these patients is down-regulation and dysfunction of $\mathrm{Cx} 43^{57-59}$. Changes in $\mathrm{Cx} 43$ expression may be regionally determined and aggravated by dyssynchronous contraction ${ }^{57,64}$. Similarly, conduction abnormalities are frequently found in patients with healed myocardial infarctions. Surviving cells in the peri-infarct zone have abnormal action potentials due to abnormal cell coupling ${ }^{53,65}$. Significant changes in GJC organization and distribution of Cx43 occur in healed myocardial infarctions ${ }^{60-62}$. In experimental studies, genetically engineered mice expressing $<50 \%$ of normal $\mathrm{Cx} 43$ levels exhibit increased propensity towards arrhythmic activity in response to acute ischemia ${ }^{66}$. Targeted inactivation of Cx43 in myocardium leads to increased arrhythmic activity and sudden death ${ }^{67,68}$. In heart failure and myocardial infarction, activation of c-Jun N-terminal kinase (JNK) appears to be the mechanism by which $\mathrm{Cx} 43$ is down-regulated ${ }^{69}$. In addition to decreasing $\mathrm{Cx} 43$ expression, phosphorylation changes impairing $\mathrm{Cx} 43$ function effectively reduce cell-to-cell communication ${ }^{58,59}$.

Conduction is further impaired in heart failure and myocardial infarction by lateralization of GJCs and increased heterogeneity of Cx isotypes in hemichannels ${ }^{60,70}$. In normal hearts, GJCs are primarily localized at the end-to-end junctions of adjacent 
myocytes. In healed myocardial infarction there are fewer and smaller GJCs, with a change in proportion of side-to-side versus end-to-end intercellular connections ${ }^{60}$. In heart failure, the percentage of lateralized GJCs expressing Cx43 increases along the length of myocytes while end-to-end connections decrease ${ }^{70}$. Furthermore, increased $\mathrm{CX} 43$ heterogeneity in heart failure patients is associated with $\mathrm{VT}^{71}$. Recent studies demonstrate that homotypic $\mathrm{Cx} 43$ and $\mathrm{Cx} 45$ GJCs have higher conductance than heterotypic and heteromeric ( $\mathrm{Cx} 43$ and $\mathrm{Cx} 45$ combined) GJCs ${ }^{72,73}$. Since $\mathrm{Cx} 43$ is downregulated in heart failure and $\mathrm{Cx} 45$ levels are unchanged or increased, the $\mathrm{Cx} 45: \mathrm{Cx} 43$ ratio increases, potentially promoting the formation of more heterogeneous GJCs with lower conductance than in normal hearts ${ }^{56,73}$.

The similarity of events in HHcy-, heart failure- and myocardial infarctioninduced remodelling supports the hypothesis that elevated levels of Hcy may create arrhythmogenic substrate. In fact, recent evidence demonstrates that long-term dietinduced HHcy down-regulates $\mathrm{Cx} 43$ expression $^{74}$. Down-regulation of $\mathrm{Cx} 43$ expression in heart failure produces a positive feedback system in which slow ventricular impulse conduction contributes to mechanical dysfunction, and further promotes ventricular remodelling ${ }^{64}$. Impaired impulse conduction also creates substrate for re-entrant arrhythmias ${ }^{57}$. These arrhythmias require two parallel conducting pathways connected proximally and distally by conducting tissue, thus forming a potential electric circuit. For re-entry to occur 3 prerequisites need to be present: 1) one of the two pathways conducts more slowly, 2) the faster conducting pathway has a substantially longer refractory period, and 3) an appropriately timed premature impulse is needed to initiate a continuous circular propagation of the impulse. In heart failure, subepicardial $\mathrm{Cx} 43$ expression is 
reduced by approximately a third compared with deeper layers of the left ventricle, accentuating uncoupling between the epicardial-midmyocardial interface ${ }^{57}$. The development of steep gradients of repolarization occurring within the epicardialmidmyocardial interface underlies the mechanism of conduction block and re-entrant arrhythmogenesis in heart failure ${ }^{70}$. However, in HHcy-induced ventricular remodelling, the levels of $\mathrm{Cx} 43$ expression and function at the various myocardial layers have not been studied, therefore it is unknown whether uncoupling of myocardial layers due to HHcy is of sufficient magnitude to create re-entrant substrate.

\section{Remodelling at the SAN and AVN}

The sinoatrial node (SAN) and atrioventricular node (AVN) are part of the heart's SCS. The SAN is specialized in pacemaking, whereas the AVN is responsible for propagating cardiac impulses from the SAN to the ventricles. The AVN has two important functions: 1) reduce impulse conduction velocity to allow time between atrial and ventricular depolarization, thereby allowing time for ventricular filling prior to systole, and 2) protect ventricles from premature aberrant beats generated in the atria. To perform their functions, both the SAN and AVN have special requirements regarding the electrical coupling between cells, which is determined by $\mathrm{Cx}$ isoform expression in GJCs. The electrical coupling of cells at the center of the SAN needs to be weak to protect them from the inhibitory electrotonic influence of hyperpolarized non-pacemaking atrial myocytes surrounding the SAN. Conversely, for the SAN to be able to drive the atrial muscle, electrical coupling should be strong in the periphery of the SAN ${ }^{75}$. Indeed, at the center of the mouse SAN there is little or no expression of high conductance $\mathrm{Cx} 40$ and 
$\mathrm{Cx} 43$ (the principal Cxs of cardiac muscle), but there is expression of lower conductance $\mathrm{Cx} 45$ and $\mathrm{Cx} 30.2$, whereas in the periphery of the SAN, Cx43 as well as $\mathrm{Cx} 45$ is expressed ${ }^{55}$. In the AVN, a similar pattern of Cx expression as in the center of the SAN is observed; cell-to-cell coupling is mediated by abundant expression of Cx30.2 and $\mathrm{Cx} 45$, and to a lesser extent expression of $\mathrm{Cx} 40^{55}$. This Cx expression pattern is likely to be in large part responsible for the slow conduction of the action potential. In heart failure patients, atrial remodelling is characterized by abnormalities of conduction, sinus node dysfunction, and structural changes along the crista terminalis. These abnormalities may be responsible in part for the increased propensity for atrial fibrillation in heart failure $^{76,77}$.

At present, it's unknown whether HHcy-induced cardiac remodelling has an effect on SAN function. However, recent evidence from electrophysiological studies indicates that in diet-induced HHcy, atrioventricular (AV) conduction is altered ${ }^{78}$. Anatomically, the AVN is not as discrete a body as the SAN, and the modern view describes it as a dual atrioventricular transmission system wherein diffuse fibers arising in the right atrium coalesce into two pathways which approach the central, compact body of the AVN ${ }^{79,80}$. The anterior pathway, which runs along the Tendon of Todaro, has been determined to be the fast (or normal) pathway with a longer refractory period. The posterior pathway, running along the tricuspid annulus, comprises the slow pathway with a shorter refractory period. The existence of dual pathways with differing conduction velocities has been hypothesized to be the substrate for $\mathrm{AV}$ nodal re-entrant supraventricular arrhythmias ${ }^{79,81}$. The question however is whether MMP-mediated GJC remodelling, induced by pathological conditions such as HHcy, alters AV nodal $\mathrm{Cx}$ 
expression (Cx30.2, $\mathrm{Cx} 45$, and $\mathrm{Cx} 40)$ to sufficiently create re-entrant substrate. Recent studies have provided biochemical evidence for the ability of $\mathrm{Cx} 30.2$ to heterooligomerize with the other cardiac $\mathrm{Cxs}^{82}$. In cells expressing $\mathrm{Cx} 43$ and $\mathrm{Cx} 45$, the introduction of $\mathrm{Cx} 30.2$ alters the properties of GJC currents to an intermediate level between that of either $\mathrm{Cx}$ alone. These intermediate properties may be explained by the formation of heteromeric GJCs or they might correspond to the aggregate of a mixture of homomeric GJCs. In contrast, when $\mathrm{Cx} 40$ and $\mathrm{Cx} 30.2$ are co-expressed, the physiological properties of GJCs are similar to those in cells expressing Cx30.2 alone; these findings can be explained by the formation of heteromeric GJCs. In these studies, $\mathrm{Cx} 45$ expression showed the most extensive overlap with regions of Cx30.2 expression; thus Cx30.2-Cx45 interactions may influence conduction in those areas ${ }^{82}$. Studies using genetically altered animals have shown that $\mathrm{Cx} 40$ deficient mice exhibit slower $\mathrm{AV}$ nodal conduction ${ }^{83}$. Conversely, mice deficient in $\mathrm{Cx} 30.2$ exhibit faster AV conduction ${ }^{54}$. The latter study demonstrates the important role $\mathrm{Cx} 30.2$ plays in the slowdown of impulse propagation across the $\mathrm{AVN}$, and in limiting the maximal number of beats conducted from atria to ventricles.

The evidence that diet-induced HHcy in mice shortens the PR interval in the ECG and the AH interval in the intracardiac electrogram suggests accelerated conduction across the $\mathrm{AVN}^{78}$. However, the mechanisms for increased $\mathrm{AVN}$ conduction were not elucidated in the study, and it remains to be determined whether AV nodal conduction changes are due to HHcy-induced GJC remodelling and/or overactivation of the NMDAR. Furthermore, an added level of complexity is presented by the potential effects of remodelling and cardiac NMDA-R activation on the slow and fast AVN pathways. To 
explore these mechanisms a multidisciplinary approach that includes electrophysiological studies in combination with molecular techniques will be needed to understand the underlying changes in conduction properties of slow and fast pathways associated with HHcy. It remains to be determined whether the AVN pathways in HHcy will become slower due to fewer GJCs, lateralization of GJCs, and decreased Cx40 expression or whether they will have accelerated conduction due to increased GJC heterogeneity with greater ratios of $\mathrm{Cx} 40$ expression, and/or increased cardiac NMDA-R stimulation.

\section{Cardiac Electrophysiological Pacing and Recording}

The advent of clinical cardiac electrophysiology studies has provided a better understanding of $\mathrm{AV}$ junctional arrhythmias and the dual $\mathrm{AV}$ nodal pathway physiology ${ }^{84}$. In the last 8 years, techniques to record intracardiac electrical activity, as well as the ability to deliver impulses to the right atrium and ventricle of mice using programmed stimulation, have been developed ${ }^{54,83,85}$. To perform the electrophysiological studies, a $2 \mathrm{Fr}$ octopolar ring electrode catheter with $0.5 \mathrm{~mm}$ electrode width and $0.5 \mathrm{~mm}$ interelectrode distance is introduced into the right atrium and ventricle of the mouse via the right external jugular vein. Once the catheter tip is placed at the apex of the right ventricle, electrode pairs are selected to stimulate and record signals from the atria, AV node, and ventricles. Basic electrophysiologic variables are obtained using standard clinical electrophysiologic pacing protocols adjusted to the murine heart rate ( 600 beats/min). Information gathered from these studies includes assessment of sinoatrial (SA)- and AV-nodal automaticity and conductivity as well as assessment of His-Purkinje system conductivity and refractoriness. It is also possible to study whether 
mice have a propensity to develop atrial or ventricular tachyarrhythmias by using stimulation protocols that include up to three premature extra stimuli. 


\section{CHAPTER II}

\section{HYPOTHESIS AND SPECIFIC AIMS}

\section{Hypothesis}

Increased plasma homocysteine (Hcy) levels cause increased activation of cardiac NMDA receptors at the sinoatrial and atrioventricular nodes, increasing intracellular calcium and enhancing excitability of nodal cells, and thereby facilitating abnormalities in sinoatrial and atrioventricular conduction. This hypothesis was tested through three specific aims.

\section{Specific Aim 1}

To determine whether increased plasma Hcy, as observed in hyperhomocysteinemia (HHcy), affects cardiac conduction, surface electrocardiographic (ECG) data was obtained and programmed electrophysiological (EP) studies were performed in vivo to characterize conduction variables in wild-type C57BL/6J mice and diet-induced hyperhomocysteinemic C57BL/6J mice. Comparison of these data may illustrate any changes to cardiac conduction due to higher levels of plasma Hcy. 


\section{Specific Aim 2}

To investigate whether cardiac NMDA-R activation is involved in normal and/or pathologic cardiac conduction, pharmacological inhibitors of the NMDA receptor were utilized and ECG and EP variables at baseline were compared with those obtained following NMDA-R blockade. ECG and EP data were collected from wild-type C57BL/6J mice, diet-induced hyperhomocysteinemic C57BL/6J mice, and geneticallyinduced hyperhomocysteinemic C57BL/6J mice. In a second set of experiments, HHcy was induced in wild-type C57BL/6J mice by intraperitoneal administration of Hcy solution in an acute infusion model.

\section{Specific Aim 3}

In order to compare expression levels of cardiac NMDA receptor in wild-type, diet- and genetically-induced hyperhomocysteinemic mice, immunoblotting was performed on hearts from animals from all three groups. Additionally, immunohistochemical identification of cardiac NMDA-R at the mouse atrioventricular node was undertaken. 


\section{CHAPTER III}

\section{HYPERHOMOCYSTEINEMIA Alters SinOATRIAL AND ATRIOVENTRICUlar CONDUCTION}

\section{Introduction}

Recently, remote telemetric ECG recordings from wild-type mice and mice with diet-induced hyperhomocysteinemia (HHcy) have been shown to display irregular cardiac rhythms ${ }^{74}$. In animals with diet-induced HHcy, long pauses in the ECG traces were recorded, indicating the presence of conduction abnormalities. HHcy is associated with hypertension, coronary artery disease, and cardiac interstitial fibrosis ${ }^{24}$. These risk factors induce structural and functional changes to the specialized conductive tissues as well as to the working myocardium, altering normal conduction. Conduction abnormalities increase the chance of creating substrate for the induction of ventricular tachycardia (VT) and possibly ventricular fibrillation (VFib). In the absence of intervention, VT degenerates into VFib and if not treated, ultimately sudden cardiac death ensues Several studies associate elevated Hcy with sudden cardiac death ${ }^{9,14,16}$. Additionally, several studies assert an association between HHcy and atrial fibrillation $^{25,28}$. Atrial fibrillation arises from extensive structural and electrical atrial remodelling. HHcy-induced MMP activation plays a role in the structural and electrical remodelling of the atria ${ }^{26,27}$. Following orthotopic heart transplantation, HHcy is 
associated with altered atrial electrical conduction manifesting as $\mathrm{P}$ wave dispersion ${ }^{28}$. Hcy also modulates sodium and potassium currents in human atrial myocytes ${ }^{29,30}$, highlighting another plausible mechanism by which elevated Hcy may initiate atrial arrhythmias.

My aim in this chapter was to investigate for the first time the electrophysiological characteristics of the cardiac conduction system in wild-type and hyperhomocysteinemic mice. The goal of these studies was to gain a better understanding of the effects of HHcy on sinoatrial and atrioventricular function. The hypothesis tested was that elevated plasma Hcy alters excitability of sinoatrial and atrioventricular nodal cells, resulting in abnormal nodal conduction.

\section{Methods}

Specific Aim 1 consisted of experiments performed on groups of 5 month old male C57BL/6J mice weighing 28-32g. In this set of studies, wild-type control mice (WT, total $n=17$ ) and long-term diet-induced HHcy mice receiving $400 \mathrm{mg} / \mathrm{L}$ of homocystine, the dimerized form of Hcy, for a period of 12 weeks in their drinking water $(D W$, total $\mathrm{n}=16$ ) were used to characterize electrocardiographic and electrophysiologic variables, including ventricular refractoriness and arrhythmia induction.

Mice were housed 5 per cage and allowed ad libitum access to food and water in a facility with 12-hour light and dark cycles. All animals were housed and cared for in accordance with the National Institutes of Health Guide for the Care and Use of Laboratory Animals (Department of Health and Human Services, Publication No. [NIH] 86-23), the Association for the Assessment and Accreditation of Laboratory Animal 
Care, and by the Institutional Animal Care and Use Committee of the University of Louisville.

\section{Electrocardiographic and EP Studies}

For each procedure, animals were anesthetized with 2,2,2-tribromoethanol (400 $\mathrm{mg} / \mathrm{kg}$ IP). Supplemental doses were administered as needed to maintain an adequate plane of anesthesia throughout the experiment. Anesthesia was monitored by checking the pedal reflex. Body temperature was maintained using a feedback system consisting of a rectal probe and a heating pad (Fine Science Tools, Foster City, CA). A lead II surface ECG was recorded during all procedures using subcutaneous needle electrodes, and RR, $\mathrm{PR}, \mathrm{QRS}$, and QT intervals were measured. Corrected QT (QTc) intervals were calculated using Bazett's formula ${ }^{86}$. A right external jugular vein cannulation was performed to advance a 2-Fr octapolar catheter (CIBer mouse-EP; NuMED Inc., Hopkinton, NY) into the right atrium and ventricle. Intracardiac bipolar recordings were performed to verify catheter placement. Intracardiac electrogram recordings were obtained using a customized Biopac MP150 recording/stimulation system controlled by Acknowledge software (Biopac Systems Inc., Goleta, CA). The catheter was manipulated to allow bipolar atrial stimulation, and recording of signals with clear visualization of the His bundle spike. The AH and HV intervals of intracardiac electrograms were measured. EP studies were performed using standard atrial and ventricular programmed stimulation protocols that were modified to accommodate mouse heart rates $(\sim 600 \mathrm{bpm})$. Mice were first paced from the right atrium and then paced from the right ventricle. Stimulation was performed using square waves with a pulse width of $2 \mathrm{~ms}$ and with DC current set at twice 
the diastolic threshold. The recording sampling rate of signals was $2 \mathrm{kHz}$. EP variables measured included: sinus node recovery time (SNRT), corrected SNRT (CSNRT), Wenckebach periodicity (WP), 2:1 AV block, AV nodal effective refractory period (AVNERP), right ventricular effective refractory period (RVERP) and arrhythmia induction using one and two premature ventricular stimuli. WP and 2:1 AV block were assessed using programmed stimulation protocols in which basic cycle trains were reduced by $2.5 \mathrm{~ms}$ decrements starting at an interval rate just below the intrinsic heart rate. The basic cycle length of trains in effective refractory period protocols was $100 \mathrm{~ms}$ (S1) and premature beats $(\mathrm{S} 2)$ were serially reduced by $5 \mathrm{~ms}$ decrements.

\section{Blood Analysis}

At the end of the EP studies, 300 to $500 \mu \mathrm{L}$ of blood were collected and centrifuged for $10 \mathrm{~min}$ at $10,000 \mathrm{rpm}$. The plasma was separated and frozen until analysis. Plasma Hcy was measured independently using a recombinant enzymatic cycling assay (Carolina Liquid Chemistries Corp., Winston-Salem, NC). The assay determines total plasma Hcy, which represents protein-bound Hcy plus free Hcy. Free Hcy encompasses the sulfhydryl form $(\mathrm{HcyH})$, the dimerized form homocystine (HcyHcy), and Hcy-cysteine mixed disulfides. Values of plasma levels are reported as mean \pm SEM. 


\section{$\underline{\text { Statistical Analysis }}$}

Unpaired $t$-tests were performed to compare the means between groups for ECG and EP variables, as well as plasma Hcy values. Values are given as mean \pm SEM for each group. A $P$ value less than 0.05 was considered significant.

\section{Results}

In the first experiment, we evaluated the effects of HHcy on surface ECG intervals, intracardiac electrograms, sinoatrial function, AV nodal conduction and ventricular conduction. Tables 1 and 2 summarize findings from this experiment. Surface ECG analysis revealed that the RR (122.2 $\pm 3.6 \mathrm{~ms}$ vs. $141.0 \pm 7.7 \mathrm{~ms}, P<0.05), \mathrm{PR}$ (46.6 $\pm 2.0 \mathrm{~ms}$ vs. $53.8 \pm 2.6 \mathrm{~ms}, P<0.05)$, and QT $(56.7 \pm 2.3 \mathrm{~ms}$ vs. $64.5 \pm 1.9 \mathrm{~ms}, P<0.05)$ intervals were significantly shortened in mice with HHcy compared to controls (Table 1). The intracardiac HV interval was significantly shortened compared to controls $(8.1 \pm 0.5$ ms vs. $10.3 \pm 0.5 \mathrm{~ms}, P<0.01)$ while the $\mathrm{AH}$ interval was not significant $(39.0 \pm 1.8 \mathrm{~ms}$ vs. 44.0 $\pm 2.3 \mathrm{~ms}, P=\mathrm{NS}$ ) in HHcy mice compared to controls (Table 1). Figure 1 shows representative surface and intracardiac electrograms obtained from $W T$ and $D W$ mice, and the shorter PR, and HV intervals observed in $D W$ mice. Programmed atrial stimulation revealed that in HHcy there was a significant shortening of CSNRT (30.9 $\pm 4.3 \mathrm{~ms}$ vs. 51.2 $\pm 3.0 \mathrm{~ms}, P<0.001)$, WP $(84.1 \pm 2.3 \mathrm{~ms}$ vs. $95.9 \pm 2.5 \mathrm{~ms}, P<0.01), 2: 1$ AV block (73.8 $\pm 1.8 \mathrm{~ms}$ vs. $81.2 \pm 2.4 \mathrm{~ms}, P<0.05)$, AVNERP $(55.9 \pm 3.0 \mathrm{~ms}$ vs. $70.0 \pm 3.2 \mathrm{~ms}$, $P<0.01)$, and RVERP $(38.1 \pm 1.9 \mathrm{~ms}$ vs. $52.8 \pm 3.3 \mathrm{~ms}, P<0.01)$ as compared to controls (Table 2). Arrhythmia induction using one and two premature ventricular beats was 
unsuccessful. Mean plasma levels of Hcy were $7.9 \pm 0.67 \mu \mathrm{mol} / \mathrm{L}$ in $W T$ vs. $11.2 \pm 1.03$ $\mu \mathrm{mol} / \mathrm{L}$ in $D W(P<0.05)$; the latter is considered to be mildly elevated. 
Table 1. Comparison of Surface ECG and Intracardiac Electrograms.

\begin{tabular}{lccc}
\hline & WT Control $(\mathbf{n = 1 7})$ & $\boldsymbol{D W}(\mathbf{n = 1 6})$ & $\boldsymbol{P}$ \\
\hline RR interval (ms) & $141.0 \pm 7.7$ & $122.2 \pm 3.6$ & $<0.05$ \\
HR (bpm) & $444.4 \pm 21.9$ & $497.6 \pm 15.4$ & NS \\
PR interval (ms) & $53.8 \pm 2.6$ & $46.6 \pm 2.0$ & NS \\
QRS duration(ms) & $18.4 \pm 0.4$ & $17.4 \pm 0.7$ & $<0.05$ \\
QT interval (ms) & $64.5 \pm 1.9$ & $56.7 \pm 2.3$ & NS \\
QTc interval (ms) & $54.6 \pm 0.8$ & $51.4 \pm 2.1$ & NS \\
AH interval (ms) & $44.0 \pm 2.3$ & $39.0 \pm 1.8$ & $<0.01$ \\
HV interval (ms) & $10.3 \pm 0.5$ & $8.1 \pm 0.5$ & NS \\
His duration (ms) & $3.3 \pm 0.1$ & $3.3 \pm 0.1$ & \\
\hline
\end{tabular}

$W T$, wild-type control; $D W$, mice receiving homocysteine $(400 \mathrm{mg} / \mathrm{L})$ in drinking water; HR, heart rate; NS, not significant. Values are mean \pm SEM. 
A. $W T$
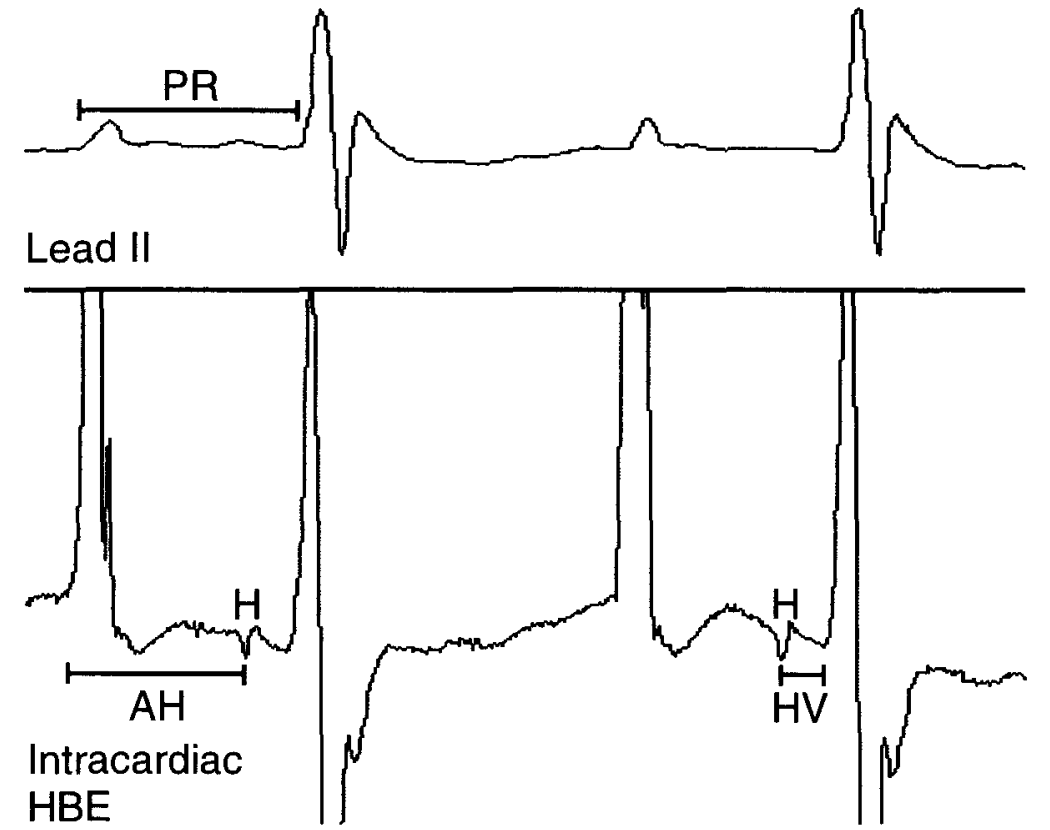

\section{B. $D W$}

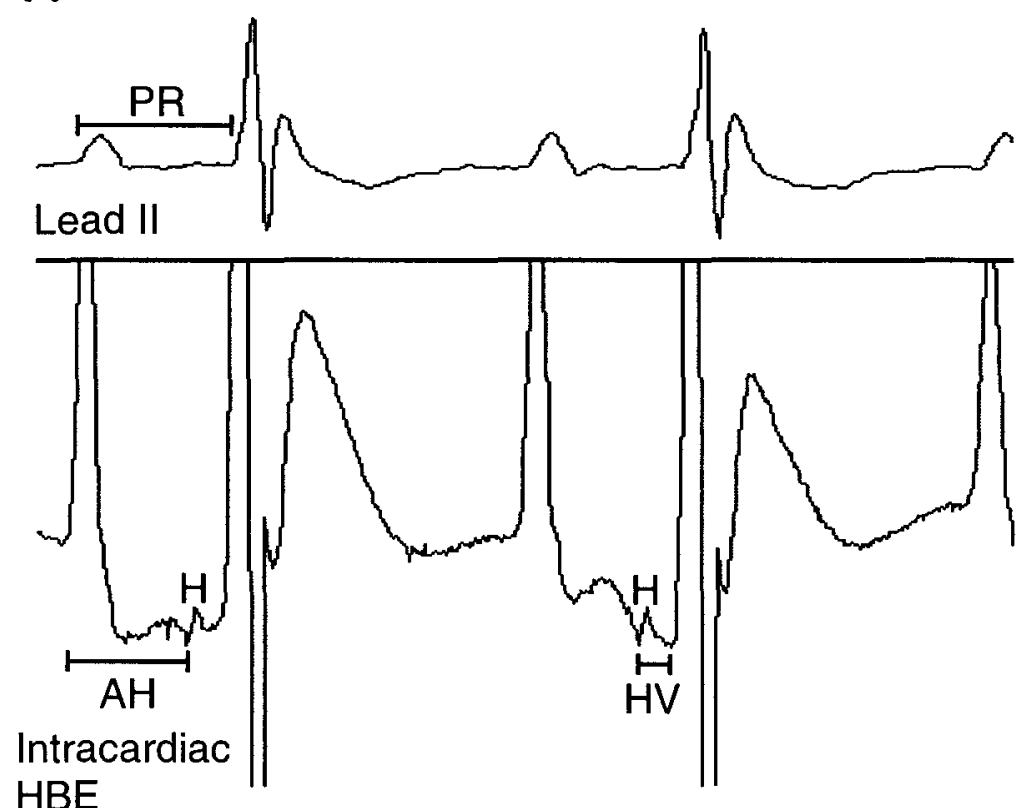

Figure 1. Representative surface ECGs and intracardiac His bundle electrograms (HBE) from: A) a wild type control (WT) mouse, and B) a mouse receiving homocysteine $(400 \mathrm{mg} / \mathrm{L})$ in the drinking water for 12 weeks $(D W)$. Notice shorter PR and HV intervals in mice receiving homocysteine compared to controls. 
Table 2. Comparison of Atrial and Ventricular Programmed Stimulation Studies.

Atrial Stimulation

\begin{tabular}{lccc}
\hline & WT Control $(\mathbf{n}=17)$ & $\boldsymbol{D W}(\mathbf{n}=\mathbf{1 6})$ & $\boldsymbol{P}$ \\
\hline CSNRT (ms) & $51.2 \pm 3.0$ & $30.9 \pm 4.3$ & $<0.001$ \\
WP (ms) & $95.9 \pm 2.5$ & $84.1 \pm 2.3$ & $<0.01$ \\
$2: 1$ AV Block (ms) & $81.2 \pm 2.4$ & $73.8 \pm 1.8$ & $<0.05$ \\
AVNERP (ms) & $70.0 \pm 3.2$ & $55.9 \pm 3.0$ & $<0.01$
\end{tabular}

Ventricular Stimulation

\begin{tabular}{lccc}
\hline & WT Control $(\mathbf{n}=9)$ & $\boldsymbol{D W}(\mathbf{n}=8)$ & $\boldsymbol{P}$ \\
\hline RVERP $(\mathrm{ms})$ & $52.8 \pm 3.3$ & $38.1 \pm 1.9$ & $<0.01$ \\
Arrhythmia induction \% & 0 & 0 & \\
\hline
\end{tabular}

$W T$, wild-type control; $D W$, mice receiving homocysteine $(400 \mathrm{mg} / \mathrm{L})$ in drinking water; CSNRT, corrected sinus node recovery time; WP, Wenckebach periodicity; AVNERP, AV-nodal effective refractory period; RVERP, right ventricular effective refractory period. Arrhythmia induction was assessed using a train of 8 beats followed by two premature beats. Values are mean \pm SEM. 


\section{Discussion}

The major finding of this study was that mild, diet-induced HHcy in mice shortens the PR and HV intervals, suggesting accelerated conduction across the AVN. These findings were supported by EP data demonstrating that CSNRT, WP, 2:1 AV block, AVNERP, and RVERP were all significantly shorter in $D W$ mice than in $W T$ mice. These results indicate SA and AV nodal conduction abnormalities in mice with mild HHcy. There are several plausible mechanisms by which elevated Hcy may account for these changes. As discussed earlier, Hcy activates NMDA receptors, as well as modulates sodium and potassium channels. Activation of cardiac NMDA receptors, especially those at the SAN and AVN, allows more calcium influx, resulting in bathmotropic and dromotropic effects. High levels of Hcy increase sodium currents while inhibiting potassium currents in human atrial myocytes ${ }^{29,30}$. Increased sodium currents enhance cell excitability, while inhibition of potassium currents prolongs action potential duration (APD). HHcy-induced modulation of cardiac sodium and potassium channels, as well as cardiac NMDA receptor activity, may produce the changes observed in this study.

Additionally, HHcy induces oxidative stress by activating inducible nitric oxide synthase (iNOS) and NADPH oxidase ${ }^{7,37,38}$. As discussed previously, increased levels of myocardial iNOS are associated with arrhythmogenesis and $\mathrm{SCD}^{87}$. HHcy increases mitochondrial oxidative stress of cardiomyocytes, increasing levels of reactive oxygen . species (ROS) which activate matrix metalloproteinases (MMPs) involved in extracellular matrix $(\mathrm{ECM})$ remodelling ${ }^{8}$. Increased activation of MMPs is responsible for abnormal myocardial remodelling, which results in increased interstitial collagen associated with fibrosis ${ }^{7}$. Homocysteine-activated MMP-mediated cardiac remodelling 
likely alters the expression, distribution, and regulation of cardiac channels and receptors, ultimately modifying electrical continuity between cardiac cells. Cardiac remodelling in patients with heart failure ${ }^{57,58,70}$, myocardial infarction ${ }^{60-62}$ and likely, HHcy, is associated with various types of arrhythmias and conduction abnormalities.

Impaired impulse conduction, as observed in this study, creates substrate for reentrant arrhythmias ${ }^{57}$. These arrhythmias require 2 parallel conducting pathways connected proximally and distally by conducting tissue, thus forming a potential re-entry or circular electrical circuit. For re-entry to occur 3 prerequisites need to be present: 1) one of the 2 pathways conducts more slowly, 2) the faster conducting pathway has a substantially longer refractory period, and, 3) an appropriately timed premature impulse is needed to initiate a continuous circular propagation of the impulse. Anatomically in the mouse and most mammals, the AVN is not a discrete entity, and the modern view describes it as a dual atrioventricular transmission system wherein diffuse fibers arising in the right atrium coalesce into two pathways which approach the central, compact body of the $\mathrm{AVN}^{79,80}$. The anterior pathway, which runs along the Tendon of Todaro, has been determined to be the fast (or normal) pathway with a longer refractory period. The posterior pathway, running along the tricuspid annulus, comprises the slow pathway with a shorter refractory period. The existence of dual pathways with differing conduction velocities has been hypothesized to be the substrate for AV nodal re-entrant supraventricular arrhythmias ${ }^{79,81}$

The mechanisms for accelerated nodal conduction were not elucidated in the study, and it remains to be determined whether SA and AV nodal conduction changes are due to HHcy-induced modulation of ion channel activity and/or MMP-induced cardiac 
remodelling. To explore these mechanisms a multidisciplinary approach that includes electrophysiological studies in combination with molecular techniques will be needed to understand the underlying changes in conduction properties associated with HHcy.

\section{Conclusions}

The results of this study show acceleration of SA nodal and AV nodal conduction in HHcy. These findings suggest that acceleration of conduction has the potential to create substrate that ultimately may lead to arrhythmogenesis. 


\title{
ChaPter IV
}

\author{
HYPERHOMOCYSTEINEMIA-INDUCED CONDUCTION ABNORMALITIES ARE \\ ASSOCIATED WITH CARDIAC NMDA RECEPTOR
}

\section{Introduction}

The NMDA receptor has been extensively studied in the CNS - its role in excitatory neurotransmission, synaptic plasticity, and memory formation has been well documented. It is known that homocysteine can activate the NMDA-R in the brain ${ }^{1}$ Extraneuronal expression of NMDA receptors has been established in the heart, lungs, kidneys, gastrointestinal tract, ovaries, and testes ${ }^{2}$. In the heart, the receptor has been identified in cardiomyocytes of the working myocardium, as well as in the specialized

conductive tissues of the heart $5^{5,6,34}$, however its function at these sites is poorly understood.

Recent studies characterizing the decrease in cardiomyocyte contractility that is observed in HHcy implicate a role for cardiac NMDA receptors. Use of MK-801, a specific non-competitive NMDA-R antagonist, attenuates the contractile dysfunction observed in $\mathrm{HHcy}^{88}$. Further studies using cardiomyocyte-specific deletion of NMDA-Rs in the murine heart also show improvements in contractile function of isolated cardiomyocytes $^{89}$. Additionally, in remote telemetric ECG studies in hyperhomocysteinemic mice treated with MK-801, significant prolongation of RR, PR, 
QRS, QT, and QTc is observed ${ }^{74}$. Animals treated with Hcy alone or MK-801 alone have prolonged QT/QTc intervals over control animals, and animals treated with both Hcy and MK-801together have even longer QT/QTc intervals. This may implicate homocysteine as well as the NMDA-R in the etiology of long QT syndrome. Taken together, it can be suggested that Hcy is acting on cardiac NMDA-Rs to effect the changes observed in HHcy.

My aim in this chapter was to investigate whether activation of cardiac NMDA receptors by Hcy underlies changes in conduction observed in diet-induced HHcy. I tested the hypothesis that elevated levels of Hcy increase activation of cardiac NMDA-Rs at the SA and AV nodes, altering sinoatrial and atrioventricular impulse conduction. The approach was to delineate a role for cardiac NMDA-Rs by comparing ECG and EP variables before and after NMDA-R blockade. A specific blocker (MK-801) and a nonspecific blocker $\left(\mathrm{MgSO}_{4}\right)$ were selected to test the hypothesis, but ultimately $\mathrm{Mg}^{2+}$ blockade proved to have fewer confounding effects and was used in the study.

\section{Materials and Methods}

\section{$\underline{\text { Study Design }}$}

Specific Aim 2 consisted of two sets of experiments performed on male C57BL/6J mice weighing 28-32g. In the first set of experiments, the feasibility of using an acute intraperitoneal infusion model of HHcy with specific NMDA-R blockade using MK-801 was explored. Hcy and MK-801 dose response studies were performed in wildtype C57BL/6J following baseline measurements of ECG and/or EP variables as described previously. ECG and EP variables were measured at 30-minute intervals for up 
to 60 minutes. Minimal doses of Hcy eliciting conduction abnormalities and minimal doses of MK-801 which did not affect conduction were sought in these experiments. Once the minimal doses were established three experimental groups were studied: Hcy only group, MK-801 only group, and Hcy and MK-801 group where MK-801 was administered 30 minutes after Hcy administration. Blood was collected at the end of each experiment for plasma analysis as described previously.

In the second set of experiments, a long-term HHcy mouse model with nonspecific NMDA-R blockade using $\mathrm{MgSO}_{4}$ was utilized. $\mathrm{Mg}^{2+}$ is an endogenous blocker of the NMDA-R, a fact which gives rise to the receptor's voltage-dependence. In a pilot study, it was determined that a dose of $20 \mathrm{mg} / \mathrm{kg}$ of $\mathrm{MgSO}_{4}$ was ideal as it did not appear to have a confounding effect on mouse ECG variables. These experiments were performed on 20 week-old male C57BL/6J and heterozygous cystathionine $\beta$-synthase knockout mice (C57BL/6J-CBS ${ }^{\text {tm1-Unc }}$ The Jackson Laboratory, Bar Harbor, ME) mice weighing $28-32 \mathrm{~g}$. A paired-design study was performed on the following groups: wildtype controls (WT, $\mathrm{n}=8$ ), diet-induced HHcy receiving $400 \mathrm{mg} / \mathrm{L}$ of homocystine in the drinking water for 12 weeks $(D W, \mathrm{n}=8)$, and C57BL/6J-CBS ${ }^{\text {tml-Unc }}$ mice $\left(C_{B S}^{+/-}, \mathrm{n}=7\right)$ were subjected to a baseline EP study followed by a repeat EP study 30 minutes after intraperitoneal (IP) administration of $\mathrm{MgSO}_{4}(20 \mathrm{mg} / \mathrm{kg})$ in phosphate buffer saline (PBS).

Mice were housed 5 per cage and allowed ad libitum access to food and water in a facility with 12-hour light and dark cycles. All animals were housed and cared for in accordance with the National Institutes of Health Guide for the Care and Use of Laboratory Animals (Department of Health and Human Services, NIH Publication No. 
86-23), the Association for the Assessment and Accreditation of Laboratory Animal Care, and by the Institutional Animal Care and Use Committee of the University of Louisville.

\section{Electrocardiographic and EP Studies}

For each procedure, animals were anesthetized with 2,2,2-tribromoethanol (400 $\mathrm{mg} / \mathrm{kg}$ IP). Supplemental doses were administered as needed to maintain adequate anesthesia throughout the experiment. Anesthesia was monitored by checking the pedal reflex. Body temperature was maintained using a feedback system consisting of a rectal probe and a heating pad (Fine Science Tools, Foster City, CA). A lead II surface ECG was recorded during all procedures using subcutaneous needle electrodes, and RR, PR, QRS, and QT intervals were measured. Corrected QT (QTc) intervals were calculated using Bazett's formula ${ }^{86}$. A right external jugular vein cannulation was performed to advance a 2-Fr octapolar catheter (CIBer mouse-EP; NuMED Inc., Hopkinton, NY) into the right atrium and ventricle. Intracardiac bipolar recordings were performed to verify catheter placement. Intracardiac electrogram recordings were obtained using a customized Biopac MP150 recording/stimulation system running Acknowledge software (Biopac Systems Inc., Goleta, CA). The catheter was manipulated to allow bipolar atrial stimulation, and clear visualization of His bundle spike. The $\mathrm{AH}$ and $\mathrm{HV}$ intervals of intracardiac electrograms were measured. EP studies were performed using standard programmed stimulation protocols that were modified to accommodate mouse heart rates $(\sim 600 \mathrm{bpm})$. The heart was paced from the right atrium. Stimulation was performed using square waves with a pulse width of $2 \mathrm{~ms}$ and with DC current set at twice the diastolic 
threshold. The recording sampling rate of signals was $2 \mathrm{kHz}$. EP variables measured include: sinus node recovery time (SNRT), corrected SNRT (CSNRT), Wenckebach periodicity (WP), 2:1 AV block, AV nodal effective refractory period (AVNERP), and arrhythmia induction using one and two premature ventricular stimuli. WP and 2:1 AV block were assessed using programmed stimulation protocols in which basic cycle trains were reduced by $2.5 \mathrm{~ms}$ decrements. The basic cycle lengths of trains in AVNERP protocols in mice receiving $\mathrm{Mg}^{2+}$ were 100,110 , and $120 \mathrm{~ms}$, and were performed when heart rates allowed it. AVNERPs from the baseline and repeat EP studies were compared at the equivalent $\mathrm{S} 1$ cycle length. Premature beats (S2) in all studies were reduced by $5 \mathrm{~ms}$ decrements.

\section{Blood Analysis}

At the end of the EP studies, 300 to $500 \mu \mathrm{L}$ of blood were collected and centrifuged for $10 \mathrm{~min}$ at $10,000 \mathrm{rpm}$. The plasma was separated and frozen until analysis. Plasma $\mathrm{Mg}^{2+}$ levels were measured using a clinical chemistry Beckman-Coulter DxC 800 instrument (Beckman-Coulter, Brea, CA). It should be pointed out that total $\mathrm{Mg}^{2+}$ levels (free + bound $\mathrm{Mg}^{2+}$ ) were measured in the present study, however, free $\mathrm{Mg}^{2+}$ constitutes the active form. Values of plasma levels are reported as mean \pm SEM. Hcy was measured independently using a recombinant enzymatic cycling assay (Carolina Liquid Chemistries Corp., Winston-Salem, NC). The assay determines total plasma Hcy, which represents protein-bound Hcy plus free Hcy. Free Hcy encompasses the sulfhydryl form ( $\mathrm{HcyH})$, the dimerized form homocystine (Hcy-Hcy), and Hcy-cysteine mixed disulfides. Values of plasma levels are reported as mean \pm SEM. 


\section{Statistical Analysis}

Single-factor ANOVA and unpaired $t$-tests were performed to compare the means between groups for ECG and EP variables, as well as plasma $\mathrm{Hcy}$ and $\mathrm{Mg}^{2+}$ values. Paired $t$-tests were performed to compare means within a group before and after $\mathrm{Mg}^{2+}$ administration. Values are given as mean \pm SEM for each group. A $P$ value less than 0.05 was considered significant.

\section{Results}

In the first set of experiments to determine minimal doses of Hcy eliciting conduction changes, acute intraperitoneal infusion of very high doses consisting of 100 and $200 \mathrm{mg} / \mathrm{kg}$ did not elicit any significant changes in PR interval, WP, 2:1 AV block, and AVNERP at 30 and 60 minutes. These findings are illustrated in Figures 2 and 3. Conversely, in experiments using the NMDA-R blocker MK-801, extremely pronounced changes in the PR interval, WP, 2:1 AV block, and AVNERP were observed following administration of blocker at very low doses $(0.05,0.16$, or $0.25 \mathrm{mg} / \mathrm{kg})$. These changes are illustrated in Figures 4 and 5. 

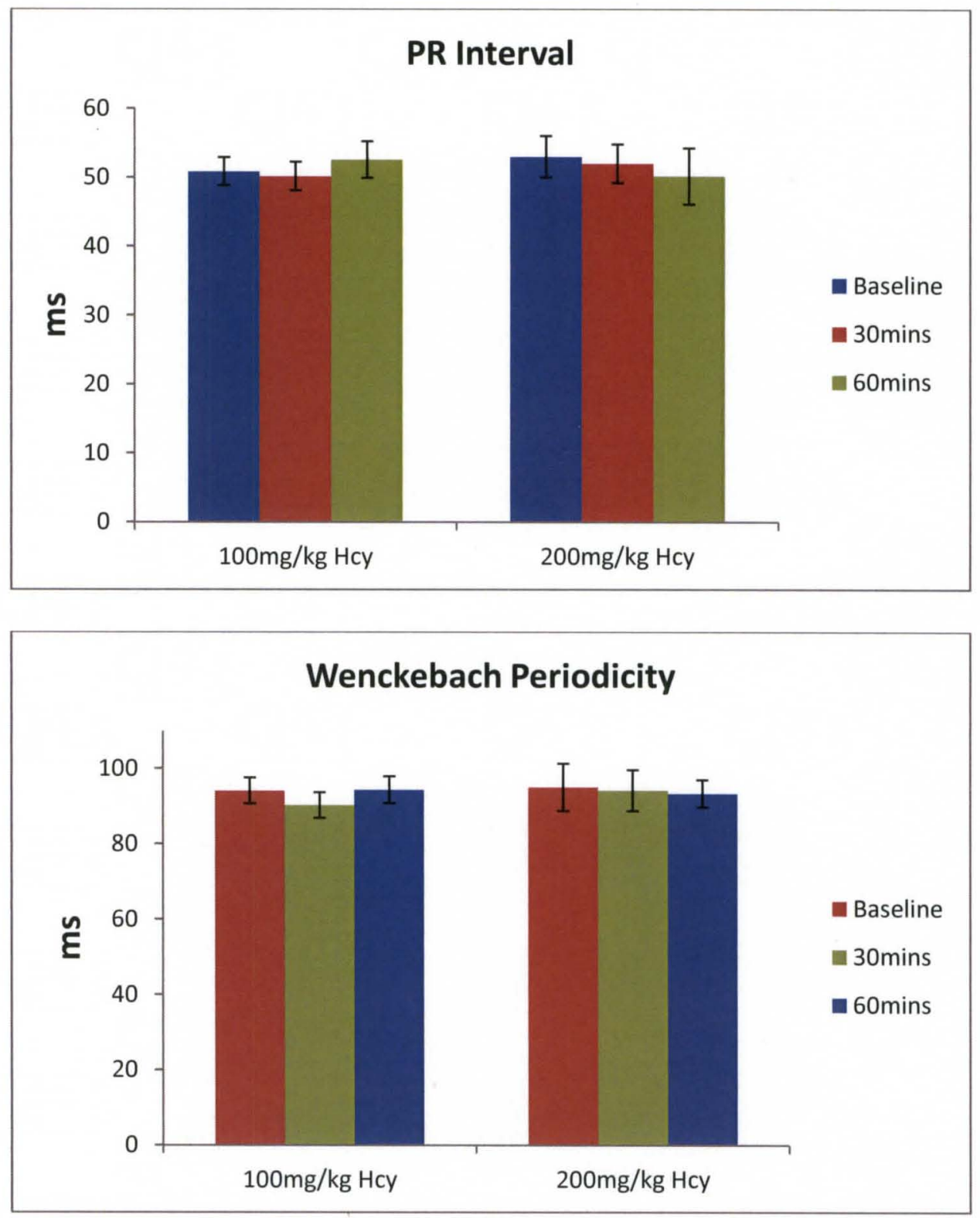

Figure 2. PR interval (top panel) and Wenckebach periodicity (bottom panel) in wild-type C57BL6 mice at 30 and 60 minutes following acute intraperitoneal administration of 100 or $200 \mathrm{mg} / \mathrm{kg}$ homocysteine 

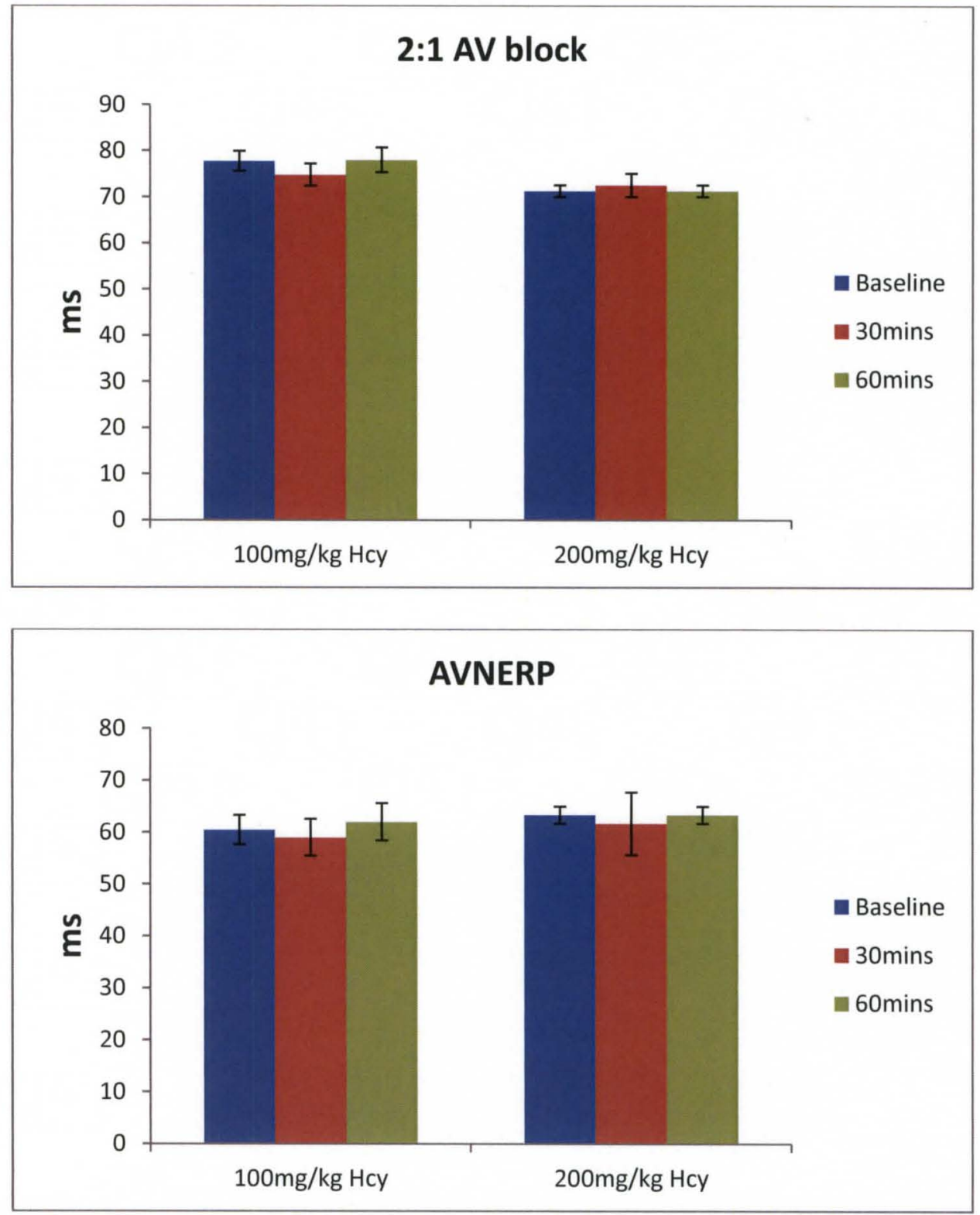

Figure 3. 2:1 AV block (top panel) and AV nodal effective refractory period (AVNERP, bottom panel) in wild-type C57BL6 mice at 30 and 60 minutes following acute intraperitoneal administration of 100 or $200 \mathrm{mg} / \mathrm{kg}$ homocysteine 

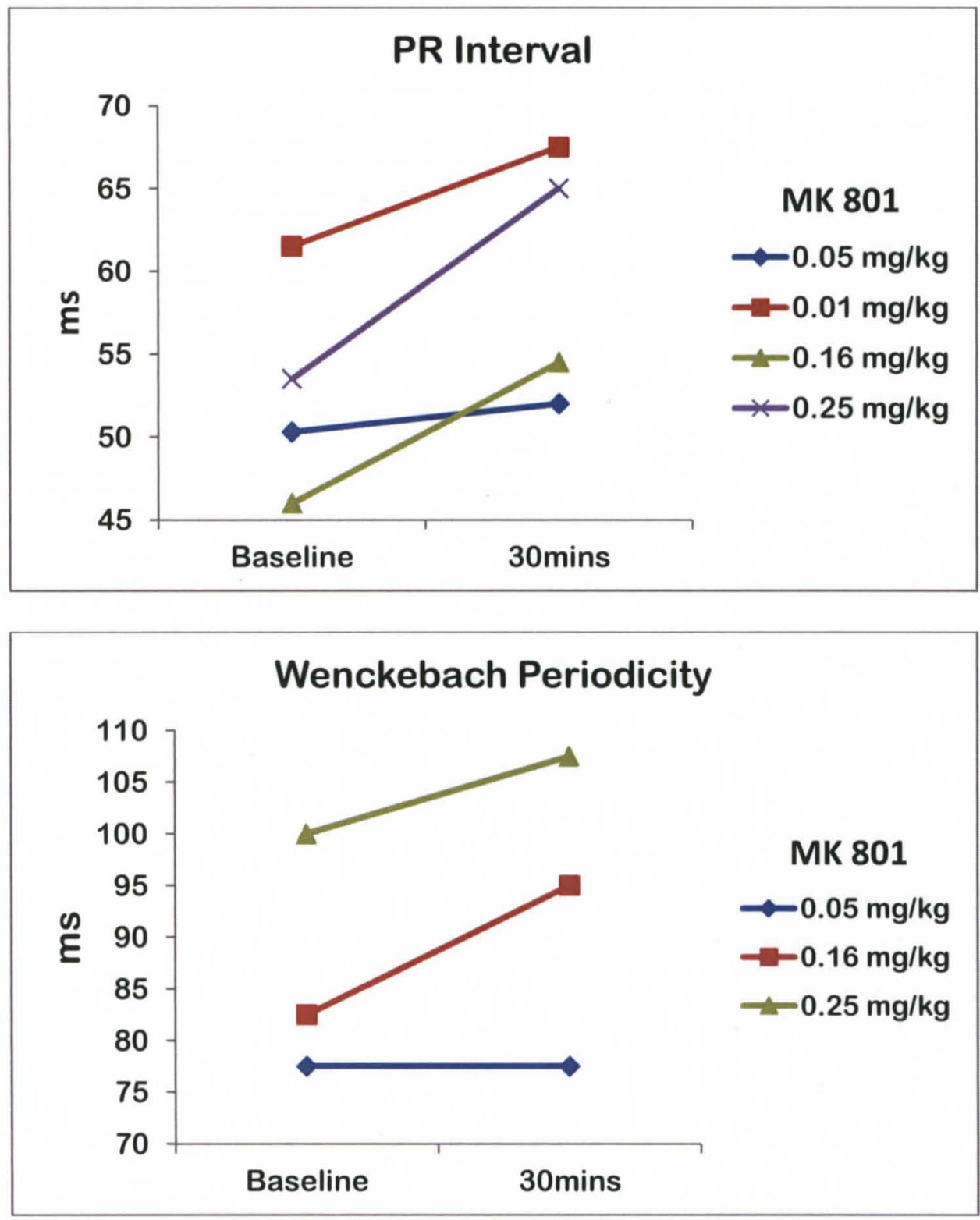

Figure 4. PR interval (top panel) and Wenckebach periodicity (bottom panel) in wild-type C57BL6 mice 30 minutes following acute intraperitoneal administration of $0.05,0.16$, or $0.25 \mathrm{mg} / \mathrm{kg}$ MK801, a non-competitive NMDA receptor antagonist. 

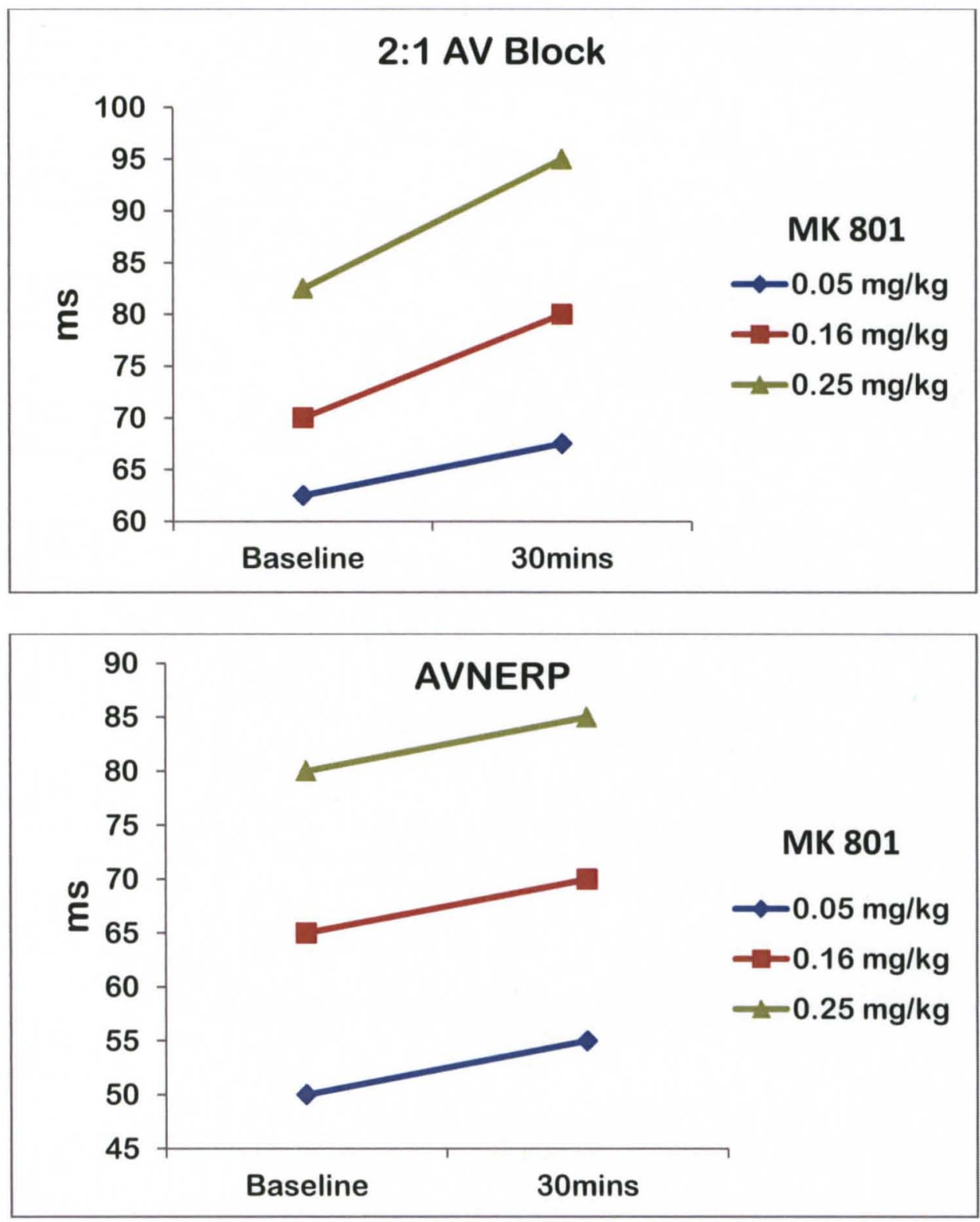

Figure 5. 2:1 AV block (top panel) and AV nodal effective refractory period (AVNERP, bottom panel) in wild-type C57BL6 mice 30 minutes following acute intraperitoneal administration of $0.05,0.16$, or $0.25 \mathrm{mg} / \mathrm{kg} \mathrm{MK} 801$, a non-competitive NMDA receptor antagonist. 
In the second set of experiments, surface ECG and intracardiac electrogram changes before and after intraperitoneal administration of $\mathrm{MgSO}_{4}(20 \mathrm{mg} / \mathrm{kg})$ in $W T, D W$ and $\mathrm{CBS}^{+-}$groups are shown in Figures 6-8. Administration of $\mathrm{Mg}^{2+}$ increased duration of RR, PR, QRS and QTc intervals, as well as $\mathrm{AH}$ and $\mathrm{HV}$ intervals in $D W$, but had little to no effect on $\mathrm{CBS}^{+/}$and $W T$ controls. Figure 9 shows EP variables before and after intraperitoneal $\mathrm{Mg}^{2+}$ in all three groups. $\mathrm{Mg}^{2+}$ administration had no effect on WT animals, but had a marked effect on both the $D W$ and $C B S^{+/ .}$animals. WP, 2:1 AV block, and AVNERP were all significantly prolonged following administration of $\mathrm{MgSO}_{4}$ in $D W$ and $C B S^{+/}$animals, and CSNRT was significantly prolonged in $D W$ mice.

There was no significant difference between $\mathrm{Mg}^{2+}$ plasma levels in all groups from blood samples collected at the end of EP studies. Normal $\mathrm{Mg}^{2+}$ plasma levels in wild-type animals before receiving intraperitoneal $\mathrm{Mg}^{2+}$ were $1.50 \pm 0.20 \mathrm{mmol} / \mathrm{L}$. In animals receiving intraperitoneal $\mathrm{Mg}^{2+}$ the levels were $1.65 \pm 0.24 \mathrm{mmol} / \mathrm{L}$ in $W T$, $1.71 \pm 0.22 \mathrm{mmol} / \mathrm{L}$ in $D W$, and $1.40 \pm 0.17 \mathrm{mmol} / \mathrm{L}$ in $C B S^{+/}$. There were significant differences in plasma Hcy levels between $W T$ mice $(8.43 \pm 2.75 \mu \mathrm{mol} / \mathrm{L}), D W$ mice $(11.16 \pm 2.91 \mu \mathrm{mol} / \mathrm{L}, P<0.02$ compared to $W T)$ and $C B S^{+/-}$mice $(13.04 \pm 4.49 \mu \mathrm{mol} / \mathrm{L}$, $P<0.02$ compared to $W T$ ). There was no difference in Hcy levels between $D W$ and $C B S^{+/}$ mice. 
A.

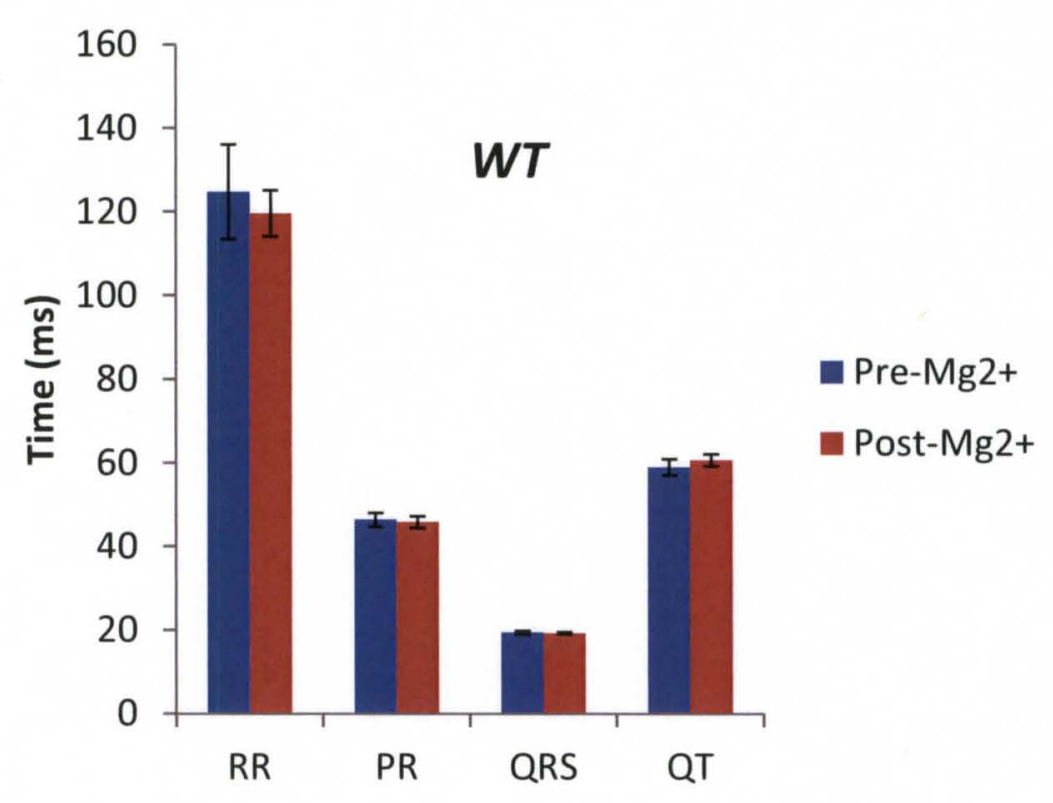

B.

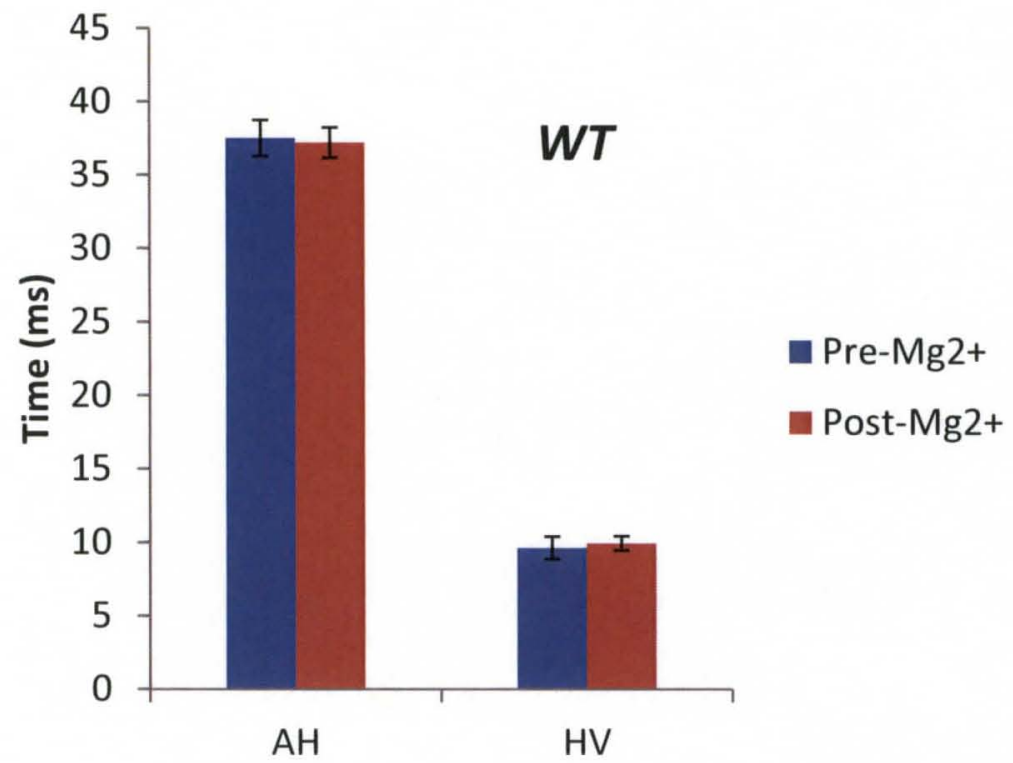

Figure 6. A. Surface ECG variables in wild-type $(W T)$ animals at baseline (Pre- $\left.\mathrm{Mg}^{2+}\right)$ and following $\mathrm{MgSO}_{4}$ administration (Post- $\mathrm{Mg}^{2+}$ ). B. Intracardiac ECG variables in WT animals at baseline (Pre- $\mathrm{Mg}^{2+}$ ) and following $\mathrm{MgSO}_{4}$ administration $\left(\right.$ Post- $\mathrm{Mg}^{2+}$ ). $\mathrm{AH}=$ Intracardiac interval measuring time between atrial depolarization and depolarization of the His bundle. HV= Intracardiac interval measuring infra-Hisian conduction. 
A.

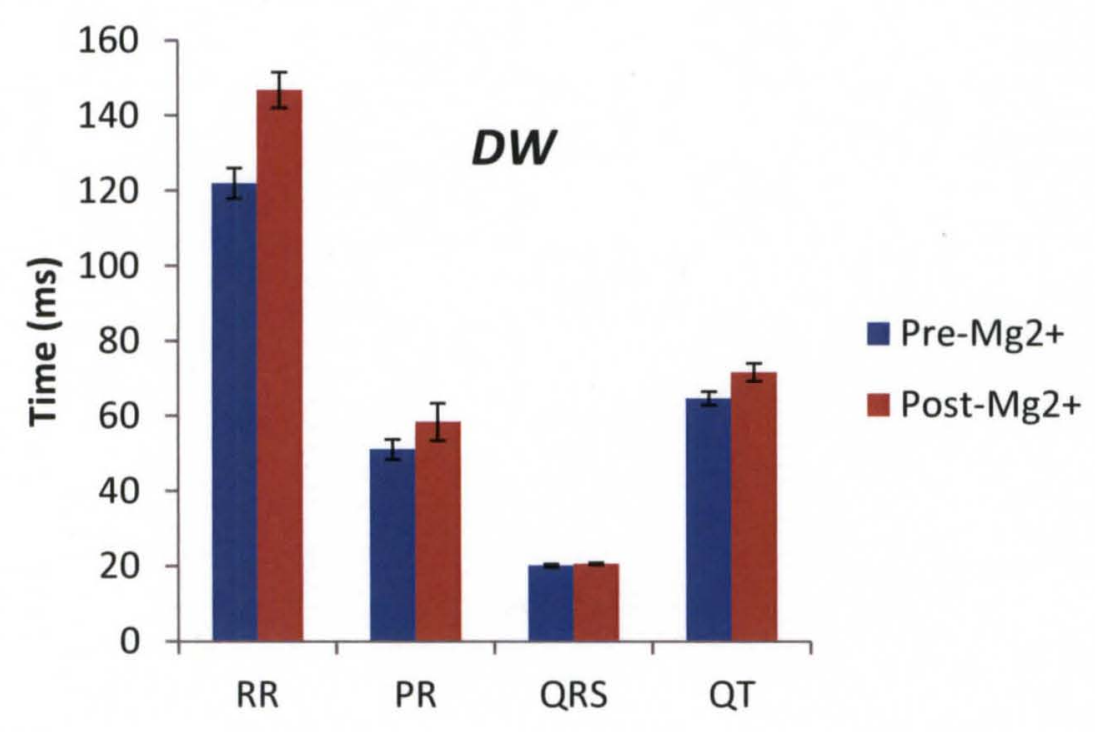

B.

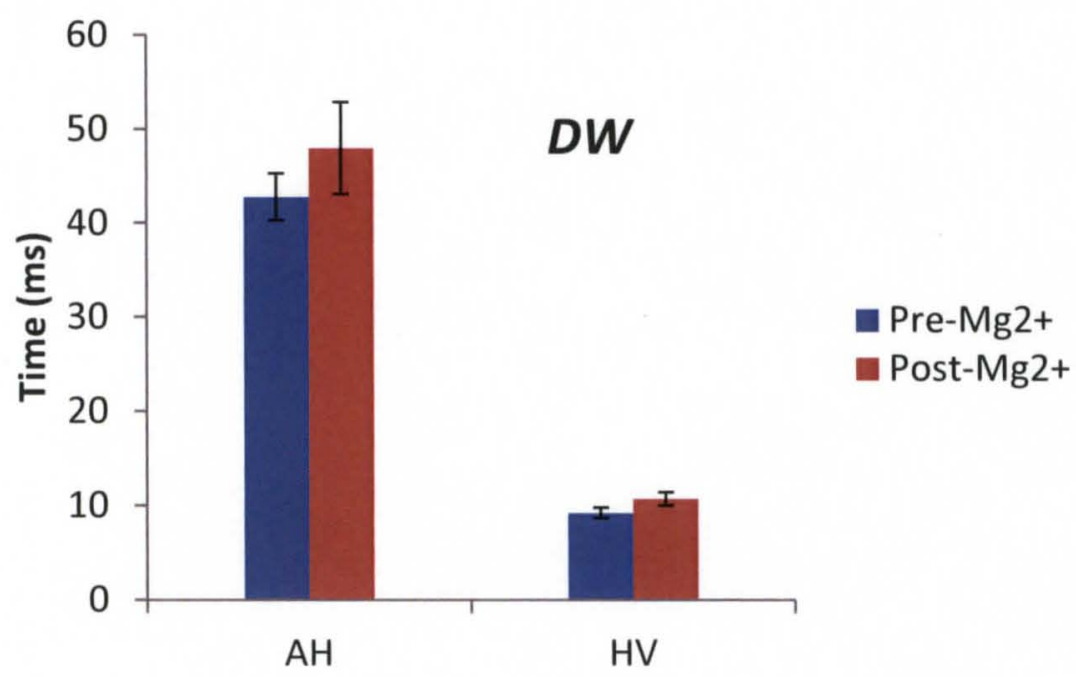

Figure 7. A. Surface ECG variables in diet-induced hyperhomocysteinemia $(D W)$ animals at baseline (Pre- $\mathrm{Mg}^{2+}$ ) and following $\mathrm{MgSO}_{4}$ administration (Post- $\mathrm{Mg}^{2+}$ ). B. Intracardiac ECG variables in $\mathrm{DW}$ animals at baseline (Pre- $\mathrm{Mg}^{2+}$ ) and following $\mathrm{MgSO}_{4}$ administration (Post- $\mathrm{Mg}^{2+}$ ). $\mathrm{AH}=$ Intracardiac interval measuring time between atrial depolarization and depolarization of the His bundle. $\mathrm{HV}=$ Intracardiac interval measuring infra-Hisian conduction. 
A.

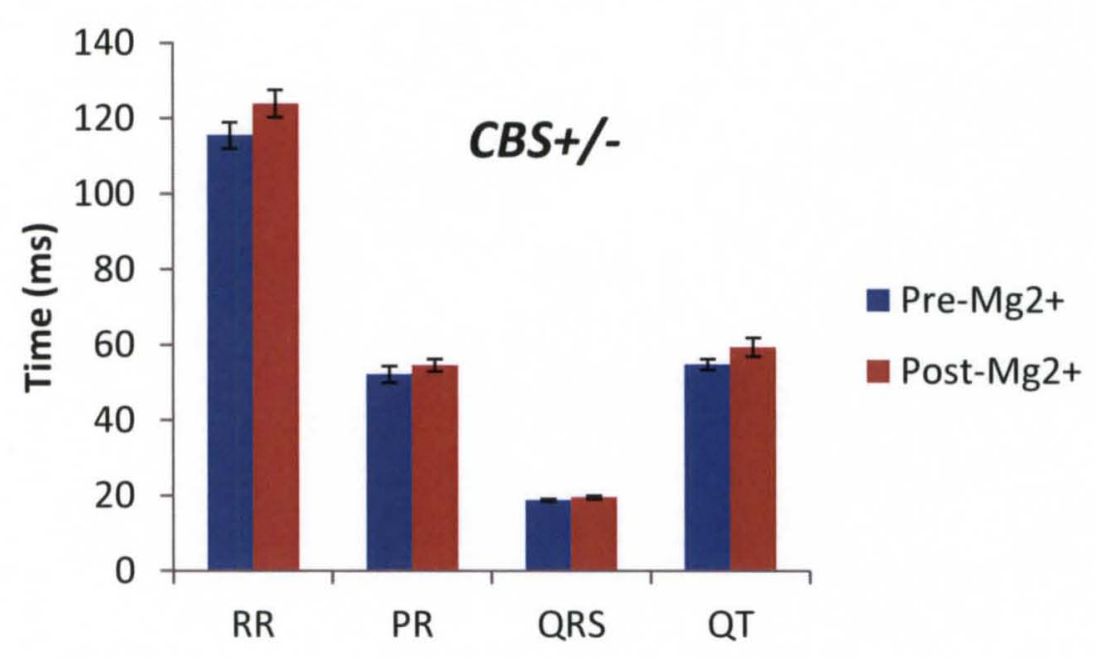

B.

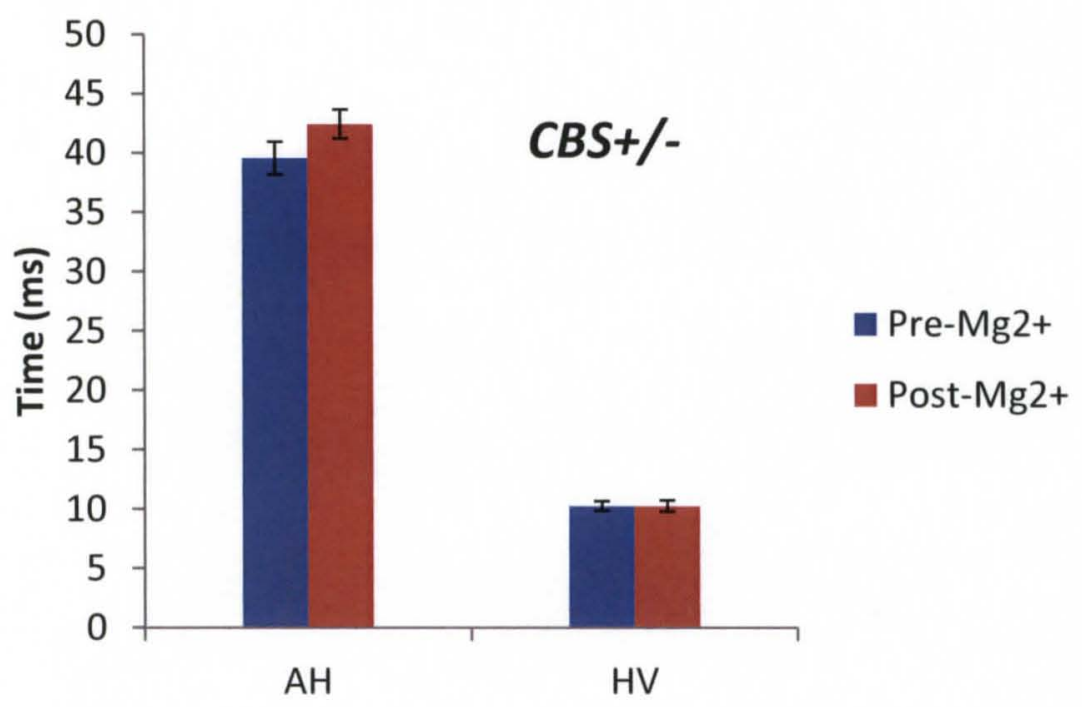

Figure 8. A. Surface ECG variables in genetically-induced hyperhomocysteinemia $\left(\mathrm{CBS}^{+/}\right)$animals at baseline (Pre- $\left.\mathrm{Mg}^{2+}\right)$ and after 30 minutes following $\mathrm{MgSO}_{4}$ administration $\left(\right.$ Post- $\mathrm{Mg}^{2+}$ ). B. Intracardiac ECG variables in $\mathrm{CBS}^{+/}$animals at baseline $\left(\right.$ Pre- $\mathrm{Mg}^{2+}$ ) and after 30 minutes following $\mathrm{MgSO}_{4}$ administration (Post- $\mathrm{Mg}^{2+}$ ). $\mathrm{AH}=$ Intracardiac interval measuring time between atrial depolarization and depolarization of the His bundle. HV= Intracardiac interval measuring infra-Hisian conduction. 
A.

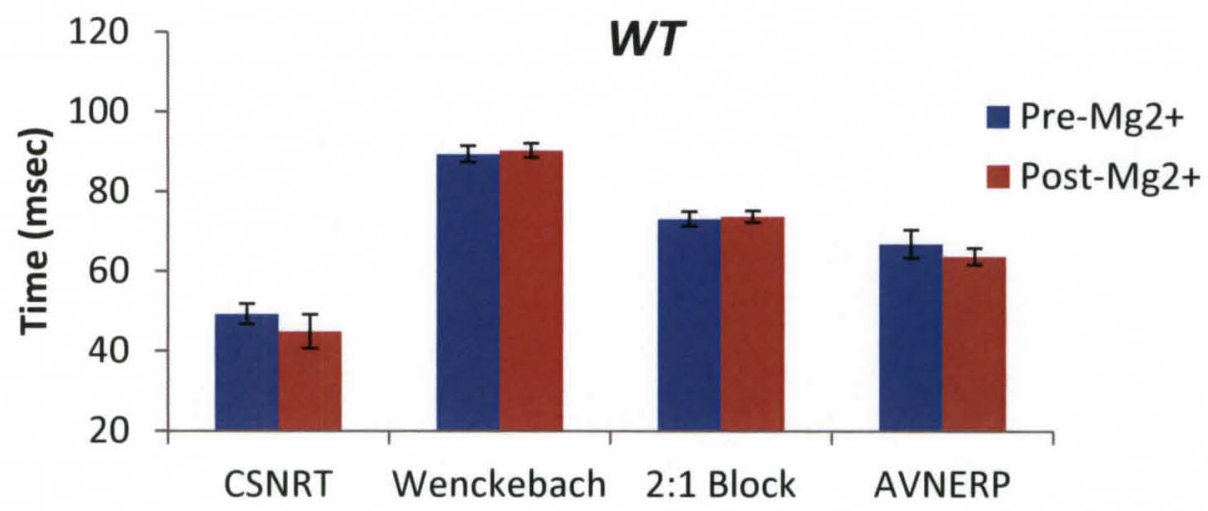

B.

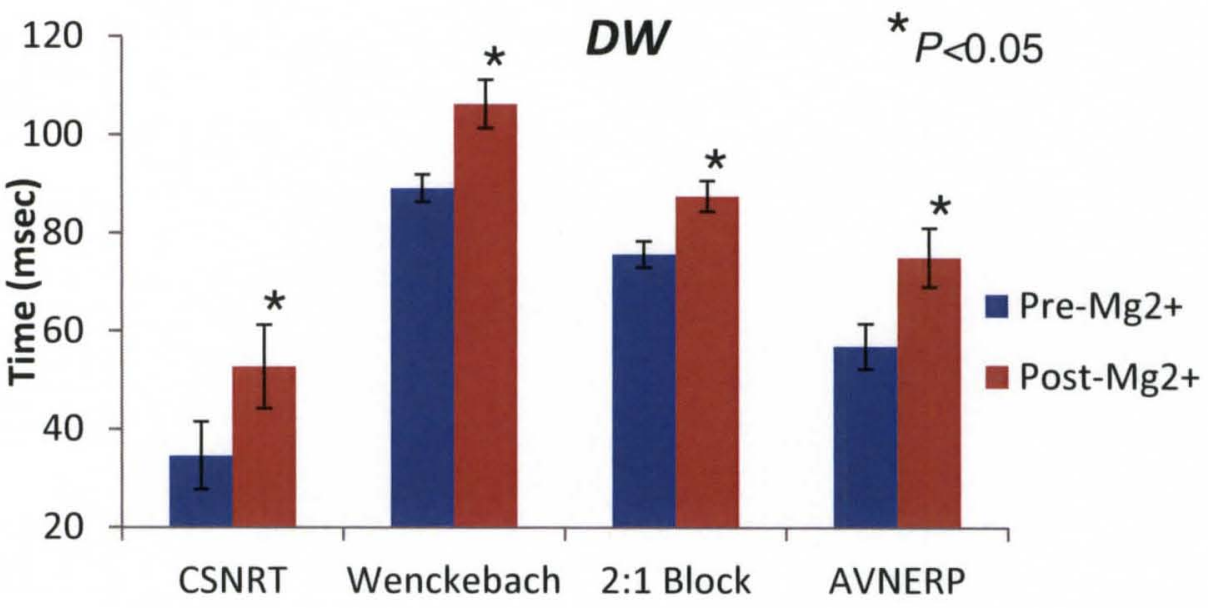

C.

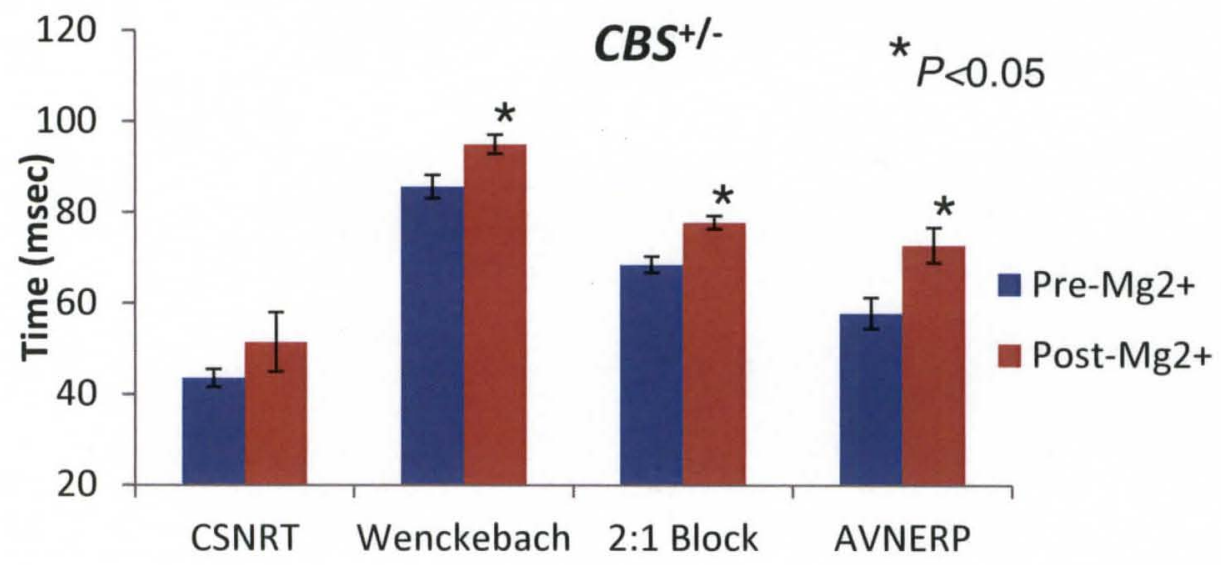

Figure 9. EP variables in wild-type (WT), diet-induced HHcy $(D W)$, and geneticallyinduced HHcy $\left(\mathrm{CBS}^{+/}\right)$animals at baseline $\left(\mathrm{Pre}-\mathrm{Mg}^{2+}\right)$ and following $\mathrm{MgSO}_{4}$ administration (Post- $\mathrm{Mg}^{2+}$ ) 


\section{Discussion}

The major finding of this study was that administration of the non-specific, endogenous NMDA- $\mathrm{R}$ antagonist $\mathrm{MgSO}_{4}$ prolonged $\mathrm{AV}$ nodal conduction in both dietinduced and genetically-induced HHcy, but not in wild-type animals. Additionally, an attempt to establish an acute model of HHcy via intraperitoneal infusion of Hcy was not successful in replicating results obtained from using chronic models of HHcy (such as dietary intake of Hcy for 12 weeks, or by genetic CBS knockout). No changes in ECG or EP variables were observed following intraperitoneal administration of high levels of Hcy, even after 120 minutes post-administration. These findings suggest that acute infusion of Hcy does not elicit the effects observed in our long-term models of chronic HHcy. Indeed, a recent report demonstrates that Hcy accumulation in tissues does not necessarily reflect plasma levels, and therefore tissue levels must be considered when analyzing the effects of plasma Hcy on target organs ${ }^{12}$.

To delineate a role for cardiac NMDA-Rs in HHcy-induced conduction abnormalities, MK-801, a specific and noncompetitive NMDA-R antagonist, was utilized. MK-801 produces sustained elevations in mean arterial pressure and heart rate when administered systemically at therapeutic doses ${ }^{90}$. Pilot studies were undertaken to determine a low dose of MK-801 which would not alter ECG and EP variables too drastically; however, at doses considerably lower than published therapeutic or experimental doses, the heart rate slowed considerably, suggesting that the blocker was inducing central effects. The use of alternative specific NMDA-R blockers (like 2-amino5-phosphonovaleric acid and memantine) was avoided because they would induce similar

effects as MK-801, affecting cardiovascular reflexes and neural tone $\mathrm{e}^{90-92}$, which would 
confound results from EP studies.

The evidence presented regarding the role of the NMDA-R in shortening AV conduction time is based on the effects of $\mathrm{Mg}^{2+}$, a known NMDA-R modulator.

Electrophysiological effects of $\mathrm{Mg}^{2+}$ have been known clinically for over 70 years. $\mathrm{Mg}^{2+}$ has been used in the management of patients with torsades de pointes, atrial flutter, paroxysmal AV re-entrant supraventricular tachycardia and Wolff-Parkinson-White (WPW) syndrome ${ }^{93,94}$. In the present study, low-dose $\mathrm{Mg}^{2+}$ blockade was selected based on results from pilot studies. In these studies, the lowest $\mathrm{Mg}^{2+}$ dose $(90 \mathrm{mg} / \mathrm{kg})$ reported to block central NMDA-Rs in rodents ${ }^{95}$ produced severe bradycardia in the C57BL/6J mice used in the present study; thus, the $\mathrm{Mg}^{2+}$ dose was further lowered to $20 \mathrm{mg} / \mathrm{kg}$, to the point where no discernible effects on heart rate or blood pressure were observed. $\mathrm{Mg}^{2+}$ blood levels at the end of the second EP study were in the normal range indicating that peak levels following IP administration were not excessively high. In the present study, this dose had no effect on ECG and EP variables in WT mice. Pilot studies determined that plasma $\mathrm{Mg}^{2+}$ levels peaked between 40 and 50 minutes following IP administration. EP studies were started 30 minutes post-administration to coincide with peak $\mathrm{Mg}^{2+}$ blood levels. Elevation of extracellular $\mathrm{Mg}^{2+}$ interferes with the release of the $\mathrm{Mg}^{2+}$ channel block present in NMDA receptors, and thus reduces inward $\mathrm{Ca}^{2+}$ flow via this channel ${ }^{95}$. In most human studies, $\mathrm{Mg}^{2+}$ administration increases cardiac conduction time to some degree; however, there is disagreement as to which conduction variables are affected. Rassmussen et al. and DiCarlo et al. demonstrate that $\mathrm{Mg}^{2+}$ treatment prolongs PR interval, QRS duration, AV nodal (AH) conduction time and AV nodal functional refractory period, but has no effect on sinus node function ${ }^{96,97}$. Alternatively, Kulick et 
al. demonstrate that $\mathrm{Mg}^{2+}$ administration prolongs $\mathrm{PR}$ interval, $\mathrm{AH}$ interval, and $\mathrm{AV}$ nodal effective refractory period but has no significant effect on QRS duration, QT interval, $\mathrm{HV}$ interval, WP, and AVNERP ${ }^{98}$. Differences reported in these studies can be attributed to the lower plasma $\mathrm{Mg}^{2+}$ levels achieved by Kulick's group. Indeed, in canine studies, low-dose $\mathrm{Mg}^{2+}$ administration elicited few conduction changes, but as dosing and levels of serum $\mathrm{Mg}^{2+}$ increase (up to $6.5 \pm 2.1 \mathrm{mmol} / \mathrm{L}$ ), a progressive prolongation in $\mathrm{AH}$ interval, HV interval, QRS duration, WP, AVNERP and RR cycle length is observed, while arterial blood pressure falls ${ }^{99}$. Thus, low-dose administration of $\mathrm{Mg}^{2+}$ appears to have little effect on cardiac conduction and EP variables. The $\mathrm{Mg}^{2+}$ dose used in the present study appears to unmask Hcy-induced effects via cardiac NMDA-Rs because changes in conduction were only observed in mice with HHcy but not in WT mice receiving the same therapy.

The findings from the present study provide modest support to the hypothesis that increased levels of Hcy overstimulate cardiac NMDA-Rs, causing an increase in intracellular calcium $\left[\mathrm{Ca}^{2+}\right]_{\mathrm{i}}$ during depolarization, leading to increased nodal cell excitation and AV nodal conduction. This hypothesis was based on literature indicating that activation of NMDA-Rs by excitatory amino acids increases intracellular calcium $\left[\mathrm{Ca}^{2+}\right]$, which in some cases leads to $\mathrm{Ca}^{2+}$ overload $^{6,100,101}$. Hcy increases NMDA-R activity by interacting with both glycine and glutamate binding sites, and the activation is enhanced when glycine levels are above normal'. Hcy-induced NMDA-R activation increases cell excitability in various cell types ${ }^{3,4,88,89,102,103}$, and the results from the present study suggest that cardiac NMDA-Rs behave similarly, particularly those expressed in $\mathrm{AV}$ nodal cells. HHcy is known to increase $\left[\mathrm{Ca}^{2+}\right]_{\mathrm{i}}$ in various cells 
expressing NMDA-Rs, including neural cells ${ }^{1,103}$, smooth muscle cells ${ }^{102}$, endothelial cells $^{3,4}$, and cardiomyocytes ${ }^{88,89}$. Although the NMDA-R is expressed in cells of the AV node, bundle of His and Purkinje fiber system, this receptor's role in normal or pathologic cardiac conduction is largely unknown. Future studies using cardiac conduction system-restricted NMDA-R knockout mice will be necessary to elucidate more specifically the mechanisms by which HHcy alters atrioventricular conduction.

\section{Conclusions}

The mechanisms associated with conduction changes observed in mild HHcy appear to involve stimulation of cardiac NMDA-Rs by Hcy. Blockade of NMDA-R with low-dose $\mathrm{Mg}^{2+}$ prolonged conduction time in animals with HHcy but had no effect on normal controls. The results of this study provide evidence that atrioventricular conduction abnormalities associated with HHcy may involve increased stimulation of AV nodal cardiac NMDA-Rs, which may provide substrate for arrhythmogenesis. 


\section{Chapter V}

CARDIAC NMDA RECEPTOR EXPRESSION IN MILD HYPERHOMOCYSTEINEMIA

\section{Introduction}

Modulation of NMDA receptors in different tissues is associated with various pathologic conditions including HHcy. Ethanol is a potent, selective inhibitor of NMDA$\mathrm{R}$ function, and chronic ethanol consumption causes an adaptive upregulation of central NMDA-R mRNA transcription as well as protein expression ${ }^{104,} 105$. In gentamicininduced nephrotoxicity, both mRNA and protein levels of the obligatory NR1 subunit of kidney NMDA-R are increased in renal proximal tubules, and treatment with the NMDA$\mathrm{R}$ antagonist MK-801 ameliorates tubular injury ${ }^{106}$. Several lines of evidence demonstrate modulation of NMDA-R expression in HHcy. Elevated homocysteine upregulates expression of NMDA receptor NR1 subunit mRNA and protein in rat aortic endothelial cells ${ }^{3}$ and rat aortic smooth muscle cells ${ }^{4}$. In uni-nephrectomized rats fed a folate-free diet for 6 weeks to induce HHcy, glomerular NR1 and NR2C subunits are upregulated, an effect that is attenuated by MK- $801^{107}$. Chronic HHcy also enhances long-term potentiation (LTP) in rat hippocampus, suggesting an upregulation of NMDA-R expression $^{108}$. In the brain, LTP underlies the processes of learning and memory formation, and is mediated by NMDA-R activity. 
In this chapter, I examined whether the electrophysiological changes observed in mild HHcy are in part explained by differences in cardiac NMDA-R expression. My aim was to investigate cardiac NMDA-R expression levels by Western blot analysis of total NMDA receptor NR1 subunit expression in whole heart, as well as to characterize NR1 expression at the murine AV node by immunohistochemical analysis. I hypothesized that NMDA-R expression levels in the heart, and in particular at the AV node, differ based on duration of exposure to elevated Hcy. To test this hypothesis, levels of cardiac NMDA-R expression were quantified, and NR1 subunit expression at the AV node was characterized.

\section{Methods}

\section{$\underline{\text { Study Design }}$}

Specific Aim 3 consisted of two sets of experiments performed on male C57BL/6J mice weighing 28-32g. In the first set of experiments, total cardiac expression of NR 1 was studied in three experimental groups of animals: wild-type control (WT, $\mathrm{n}=3$ ), diet-induced HHcy receiving $400 \mathrm{mg} / \mathrm{L}$ of homocystine in the drinking water

for 12 weeks $(D W, \mathrm{n}=3)$, and heterozygous CBS knockouts $\left(C B S^{+/}, \mathrm{n}=3\right)$. In the second set of experiments, wild-type ( $W T, \mathrm{n}=4) \mathrm{C} 57 \mathrm{BL} / 6 \mathrm{~J}$ mice were utilized for immunohistochemical identification of NMDA receptor NR1 subunit at the murine AV node. 


\section{Western Blotting}

Hearts from $W T, D W$, and $C B S^{+/-}$mice were harvested at the end of the experiment and frozen in liquid nitrogen. Cardiac tissue homogenates were prepared from whole hearts using protein extraction buffer (RIPA buffer, Sigma Aldrich, St. Louis, MO). The extracted protein was collected by centrifugation at $1500 \mathrm{~g}$ for 10 minutes. The supernatant was collected and centrifuged again until the aqueous portion was clear. Protein content was estimated using a BCA protein assay kit (Thermo Scientific, Rockford, IL). Equal amounts of protein were separated by SDS-PAGE on $12 \%$ Trisglycine gels (Bio-Rad), transferred onto PVDF membrane overnight, and probed with a polyclonal anti-NR1 antibody (Abcam Inc., Cambridge, MA) conjugated with horseradish peroxidase (HRP). Enhanced chemiluminescence reagents were applied and band intensity was recorded and analyzed with a Kodak image analyzer (Perkin-Elmer, Waltham, MA)

\section{Immunohistochemistry}

Hearts from $W T$ mice were harvested and fixed by coronary perfusion with $8 \%$ paraformaldehyde. The free wall of the right ventricle was removed, as was most of the right atrium, in order to gain access to the AV junction. Tissue samples were stored in $8 \%$ paraformaldehyde until they were embedded in paraffin (a suture was tied to the apex of the heart for orientation), and sectioned transversely beginning at a level just superior of the tricuspid valve. HRP-conjugated polyclonal anti-NR 1 antibody (Abcam Inc., Cambridge, MA) was used to probe for NMDA-R expression. Diaminobenzidine (DAB) was used as a chromogen. 


\section{Statistics}

Single-factor ANOVA and unpaired $t$-tests were performed to test for significance between groups. Values are given as mean \pm SEM for each group. A $P$ value less than 0.05 was considered significant.

\section{Results}

To characterize and compare cardiac NMDA-R expression in hearts from the three experimental groups, Western blotting for NMDA receptor NR 1 subunit in whole heart was performed. Western blotting analysis showed a significant decrease of NR1 expression in $\mathrm{CBS}^{+/-}$hearts compared to $W T$ hearts $(P<0.05)$ and $D W$ hearts $(P<0.05)$. Figure 10 shows the densitometric means from the three groups.

In order to identify NMDA-R NR 1 subunit expression at the murine AV node, immunohistochemical analysis of dissected AV junction tissue was undertaken. Figures 11-12 show representative images of sections of AV tissue stained with hematoxylin and eosin, and probed for NR1 expression. Positive immunoreactivity for NR 1 is indicated by brown punctate staining as well as diffuse brown staining of tissue. These results were difficult to interpret since the AV node is not a discrete structure that is easily identified due to the small size of mouse heart. 


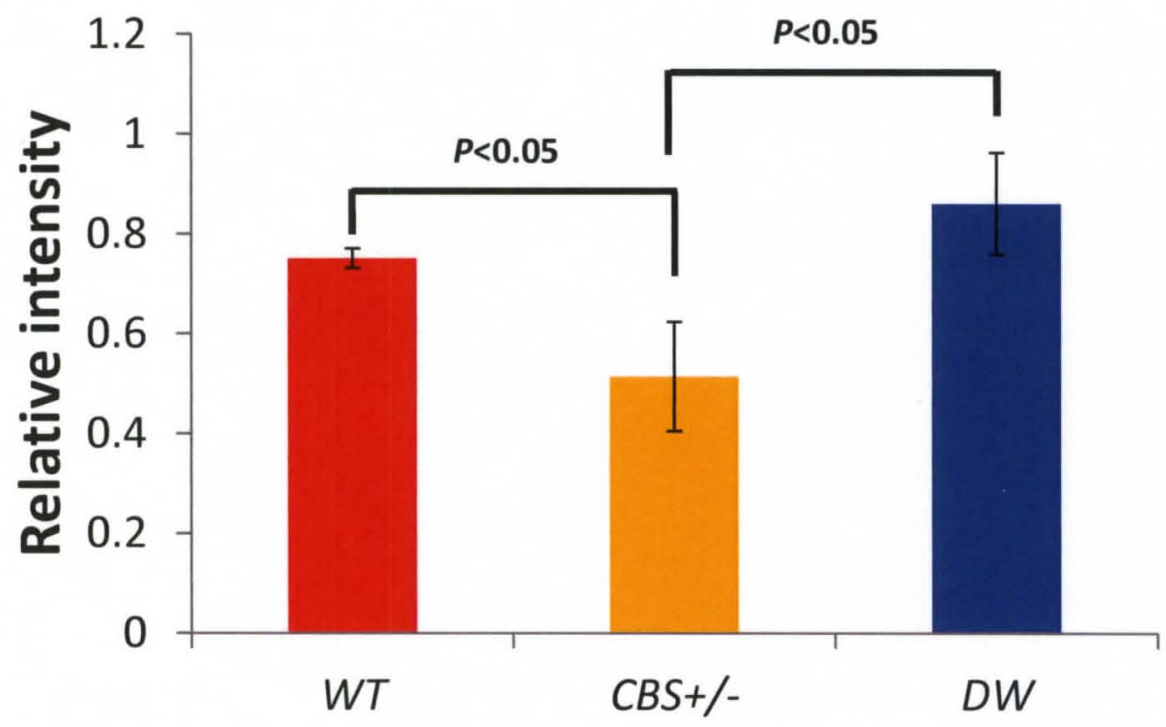

Figure 10. Relative abundance of NR1 subunit of NMDA receptor in wild-type (WT, $\mathrm{n}=3)$, genetically-induced hyperhomocysteinemic $\left(\mathrm{CBS}^{+/}, \mathrm{n}=3\right)$, and diet-induced hyperhomocysteinemic $(D W, \mathrm{n}=3)$ mouse hearts. NR1 expression in $\mathrm{CBS}^{+/}$is significantly decreased compared to $W T$ as well as $D W$. 


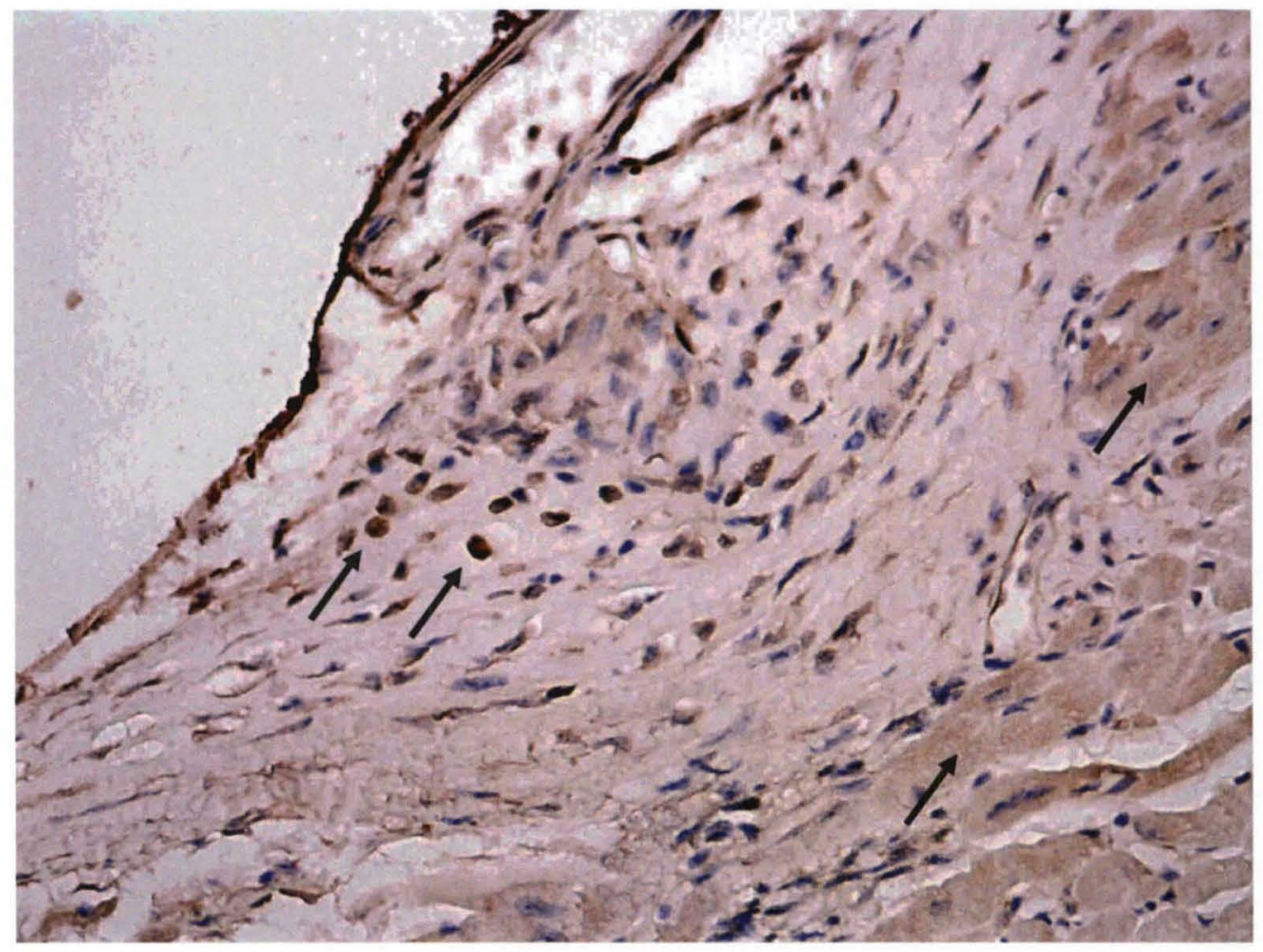

Figure 11. Tissue at the murine atrioventricular junction stained with hematoxylin and eosin and probed with anti-NR1 polyclonal antibody conjugated with horseradish peroxidase. Diaminobenzidine was used as a chromogen. 20X magnification shown. Positive immunoreactivity for NR1 is indicated by brown punctate staining as well as diffuse brown staining of cardiomyocytes (arrows). 

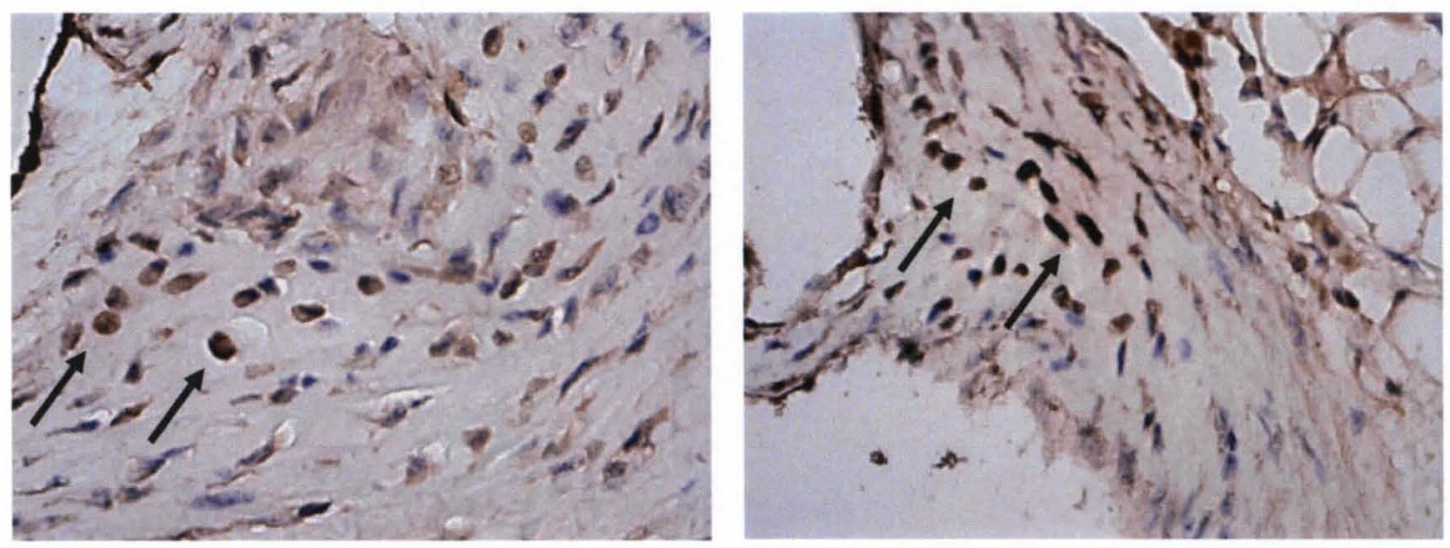

Figure 12. Tissue at the murine atrioventricular junction stained with hematoxylin and eosin and probed with anti-NR1 polyclonal antibody conjugated with horseradish peroxidase. Diaminobenzidine was used as a chromogen. 40X magnification shown. Positive immunoreactivity for NR1 is indicated by brown punctate staining (arrows). 


\section{Discussion}

The major finding from this study was that in life-long, genetically-induced HHcy, the cardiac NMDA-R appears to be down-regulated compared to WT animals as well as animals with diet-induced HHcy. The difference in NMDA-R NR1 subunit expression between the $C B S^{+/-}$and $D W$ groups may be associated with the duration of exposure to elevated Hcy, life-long versus 12 weeks respectively. The results suggest that life-long HHcy in $\mathrm{CBS}^{+/}$mice induces a down-regulation of cardiac NMDA-R expression. Interestingly, plasma Hcy levels were similar in $\mathrm{CBS}^{+/}$and $D W$ groups; however down-regulation of cardiac NMDA-R NR 1 subunit expression was only observed in $C B S^{+/}$. Moreover, NR 1 expression was significantly higher in $D W$ compared to $C B S^{+/}$. In the literature, conflicting evidence exists regarding the effect of increased agonism of NMDA-R in different cells/tissues on receptor expression. A rapid downregulation (within 3 hours) of NMDA-R NR1 subunit occurs when cerebellar granule cells are treated with NMDA, the most potent agonist of the receptor ${ }^{109}$. Other studies demonstrate upregulation of NR1 in HHcy. In cultured rat aortic endothelial cells, simulating moderate levels of HHcy ( $50 \mu \mathrm{M}$ of Hcy) causes increasing NR 1 subunit expression that peaks at 6 hours $^{3}$. In rat vascular smooth muscle cells, moderate levels of HHcy produce an increase in expression of NR1 which peaks at 12 hours post-treatment ${ }^{4}$. In vivo studies using uni-nephrectomized rats fed a folate-free diet for 6 weeks to induce mild HHcy demonstrate upregulated glomerular NRI expression ${ }^{107}$. Based on these studies, the expectation was that an upregulation of cardiac NMDA-R would occur in $\mathrm{CBS}^{+/}$and $\mathrm{DW}$ animals. However, a down-regulation was observed in $\mathrm{CBS}^{+/}$animals compared to $W T$, and no change was observed in $D W$ animals compared to $W T$ animals. 
A plausible explanation for the findings in $C B S^{+-}$mice is that in life-long HHcy, a compensatory down-regulation of NMDA-R expression in the heart may occur during early embryonic development, and expression remains down-regulated throughout adulthood. An explanation as to why $D W$ animals did not demonstrate upregulation of NR1 may be related to the lower plasma levels of Hcy achieved in $D W$ mice $(11.36 \pm 1.03$ $\mu \mathrm{M})$ compared to those reached $(16 \mu \mathrm{M})$ in uni-nephrectomized rats fed a folate-free diet, which did exhibit upregulation of glomerular NR1 expression. Thus it appears that receptor agonism can induce both upregulation and/or down-regulation of NMDA-R expression in different tissues, and is dependent on the agonist used as well as the duration of exposure to the agonist. Elevated Hcy primarily upregulates short-term receptor expression, but modulation may be dependent on plasma Hcy levels. Furthermore, modulation of receptor expression may be dependent on tissue type; in the present study, expression of NMDA-R in heart may exhibit decreased propensity towards upregulation as compared to the kidney, as observed in animals fed a folate-free diet for 6 weeks ${ }^{107}$.

NR1 expression in the cardiac conduction system has been successfully characterized in larger mammals, such as rat, primate, and human. The larger size of the hearts in these animals precludes the difficulties associated with micro-dissection of a very small region of tissue. Prior immunohistochemical characterization of NR1 expression at the murine AV node had not been accomplished, possibly due to the small size of the mouse heart and the technical challenges inherent in micro-dissection of murine AV nodal tissue. Notwithstanding this challenge, to this author's knowledge this is the first attempt to identify NMDA-R expression at the AV junction in mouse heart. 


\section{Conclusions}

Expression levels of cardiac NMDA-R were significantly decreased in genetically-induced HHcy, compared to diet-induced HHcy and controls. It appears that the electrophysiological changes observed in animals with HHcy are not due to receptor modulation, since the electrophysiologically-similar $C B S^{+-}$and $D W$ animals exhibited significantly dissimilar cardiac NMDA-R expression levels. 


\section{ChaPTER VI}

\section{SUMMARY AND FUTURE DIRECTIONS}

Hyperhomocysteinemia (HHcy) is a risk factor for cardiac arrhythmogenesis. Increased plasma homocysteine (Hcy) accelerates sinoatrial and atrioventricular conduction, as measured by electrophysiological studies. These findings suggest that acceleration of conduction has the potential to create substrate which ultimately may lead to arrhythmogenesis.

The mechanisms associated with conduction changes observed in mild HHcy appear to involve stimulation of cardiac N-methyl-D-aspartate receptors (NMDA-Rs) by Hcy. Blockade of NMDA-R with low-dose $\mathrm{Mg}^{2+}$ prolonged conduction time in animals with HHcy but had no effect on normal controls. Sinoatrial and atrioventricular conduction abnormalities associated with HHcy may involve increased stimulation of nodal cardiac NMDA-Rs, which may provide substrate for arrhythmogenesis.

Expression levels of cardiac NMDA-R were significantly decreased in genetically-induced HHcy, compared to diet-induced HHcy and controls. It appears that the electrophysiological changes observed in animals with HHcy are not due to receptor modulation, since the electrophysiologically-similar $C B S^{+/}$and $D W$ animals exhibited significantly dissimilar cardiac NMDA-R expression levels. 
Future investigation is necessary to unequivocally determine the role of cardiac NMDA$\mathrm{R}$ in Hcy-induced arrhythmias. Conditional knock-out technology, wherein genetic deletion of the protein of interest can be limited to one organ or one tissue, may be used to further delineate the role of cardiac NMDA-R in normal or pathological cardiac conduction. Additionally, it is necessary to investigate all known pathways in which Hcy exerts an influence. It may be through a direct interaction with a receptor like the cardiac NMDA-R, or through indirect means involving activation of MMPs and subsequent cardiac remodelling, that Hcy is able to evoke conduction abnormalities which underlie arrhythmogenesis. 


\section{REFERENCES}

(1) Lipton SA, Kim WK, Choi YB, Kumar S, D'Emilia DM, Rayudu PV, Arnelle DR, Stamler JS. Neurotoxicity associated with dual actions of homocysteine at the N-methyl-D-aspartate receptor. Proc Natl Acad Sci U S A 1997 May 27;94(11):5923-8.

(2) Gill SS, Pulido OM. Glutamate receptors in peripheral tissues: current knowledge, future research, and implications for toxicology. Toxicol Pathol 2001 March;29(2):208-23.

(3) Chen H, Fitzgerald R, Brown AT, Qureshi I, Breckenridge J, Kazi R, Wang Y, Wu Y, Zhang X, Mukunyadzi P, Eidt J, Moursi MM. Identification of a homocysteine receptor in the peripheral endothelium and its role in proliferation. J Vasc Surg 2005 May;4 1(5):853-60.

(4) Qureshi I, Chen H, Brown AT, Fitzgerald R, Zhang X, Breckenridge J, Kazi R, Crocker AJ, Stuhlinger MC, Lin K, Cooke JP, Eidt JF, Moursi MM. Homocysteine-induced vascular dysregulation is mediated by the NMDA receptor. Vasc Med 2005 August;10(3):215-23.

(5) Mueller RW, Gill SS, Pulido OM. The monkey (Macaca fascicularis) heart neural structures and conducting system: an immunochemical study of selected neural biomarkers and glutamate receptors. Toxicol Pathol 2003 March;31(2):227-34.

(6) Gill S, Veinot J, Kavanagh M, Pulido O. Human heart glutamate receptors implications for toxicology, food safety, and drug discovery. Toxicol Pathol 2007;35(3):411-7.

(7) Tyagi N, Moshal KS, Ovechkin AV, Rodriguez W, Steed M, Henderson B, Roberts AM, Joshua IG, Tyagi SC. Mitochondrial mechanism of oxidative stress and systemic hypertension in hyperhomocysteinemia. $J$ Cell Biochem 2005 November 1;96(4):665-71.

(8) Moshal KS, Singh M, Sen U, Rosenberger DS, Henderson B, Tyagi N, Zhang $\mathrm{H}$, Tyagi SC. Homocysteine-mediated activation and mitochondrial translocation of calpain regulates MMP-9 in MVEC. Am J Physiol Heart Circ Physiol 2006 December;291(6):H2825-H2835.

(9) James TN, Carson NA, Froggatt P. De subitaneis mortibus. IV. Coronary vessels and conduction system in homocystinuria. Circulation 1974 February;49(2):367-74. 
(10) Frosst P, Blom HJ, Milos R, Goyette P, Sheppard CA, Matthews RG, Boers GJ, den HM, Kluijtmans LA, van den Heuvel LP, . A candidate genetic risk factor for vascular disease: a common mutation in methylenetetrahydrofolate reductase. Nat Genet 1995 May;10(1):111-3.

(11) Meier M, Oliveriusova J, Kraus JP, Burkhard P. Structural insights into mutations of cystathionine beta-synthase. Biochim Biophys Acta 2003 April 11;1647(1-2):206-13.

(12) Wilson FA, van den Borne JJ, Calder AG, O'Kennedy N, Holtrop G, Rees WD, Lobley GE. Tissue methionine cycle activity and homocysteine metabolism in female rats: impact of dietary methionine and folate plus choline. Am J Physiol Endocrinol Metab 2009 April;296(4):E702-E713.

(13) McCully KS, Wilson RB. Homocysteine theory of arteriosclerosis. Atherosclerosis 1975 September;22(2):215-27.

(14) Burke AP, Fonseca V, Kolodgie F, Zieske A, Fink L, Virmani R. Increased serum homocysteine and sudden death resulting from coronary atherosclerosis with fibrous plaques. Arterioscler Thromb Vasc Biol 2002 November 1;22(11):1936-41.

(15) Tribouilloy CM, Peltier M, Iannetta Peltier MC, Trojette F, Andrejak M, Lesbre JP. Plasma homocysteine and severity of thoracic aortic atherosclerosis. Chest 2000 December; $118(6): 1685-9$.

(16) Bollani G, Ferrari R, Bersatti F, Ferrari M, Cattaneo M, Zighetti ML, Visioli O, Assanelli D. [A hyperhomocysteinemia study in a population with a familial factor for acute myocardial infarct and sudden cardiac death at a young age]. Cardiologia 1999 January;44(1):75-81.

(17) Nygard O, Nordrehaug JE, Refsum H, Ueland PM, Farstad M, Vollset SE. Plasma homocysteine levels and mortality in patients with coronary artery disease. N Engl J Med 1997 July 24;337(4):230-6.

(18) Ma J, Stampfer MJ, Hennekens CH, Frosst P, Selhub J, Horsford J, Malinow MR, Willett WC, Rozen R. Methylenetetrahydrofolate reductase polymorphism, plasma folate, homocysteine, and risk of myocardial infarction in US physicians. Circulation 1996 November 15;94(10):2410-6.

(19) Perry IJ, Refsum H, Morris RW, Ebrahim SB, Ueland PM, Shaper AG. Prospective study of serum total homocysteine concentration and risk of stroke in middle-aged British men. Lancet 1995 November 25;346(8987):1395-8.

(20) Tsai JC, Perrella MA, Yoshizumi M, Hsieh CM, Haber E, Schlegel R, Lee ME. Promotion of vascular smooth muscle cell growth by homocysteine: a link to atherosclerosis. Proc Natl Acad Sci U S A 1994 July 5;91(14):6369-73. 
(21) Israelsson B, Brattstrom LE, Hultberg BL. Homocysteine and myocardial infarction. Atherosclerosis 1988 June;71(2-3):227-33.

(22) Shimano M, Inden Y, Tsuji Y, Kamiya H, Uchikawa T, Shibata R, Murohara T. Circulating homocysteine levels in patients with radiofrequency catheter ablation for atrial fibrillation. Europace 2008 August;10(8):961-6.

(23) Marcucci R, Betti I, Cecchi E, Poli D, Giusti B, Fedi S, Lapini I, Abbate R, Gensini GF, Prisco D. Hyperhomocysteinemia and vitamin B6 deficiency: new risk markers for nonvalvular atrial fibrillation? Am Heart $J 2004$ September;148(3):456-61.

(24) Miller A, Mujumdar V, Palmer L, Bower JD, Tyagi SC. Reversal of endocardial endothelial dysfunction by folic acid in homocysteinemic hypertensive rats. $A m$ J Hypertens 2002 February; 15(2 Pt 1):157-63.

(25) Naji F, Suran D, Kanic V, Vokac D, Sabovic M. High homocysteine levels predict the recurrence of atrial fibrillation after successful electrical cardioversion. Int Heart J 2010 January;51(1):30-3.

(26) Arndt M, Lendeckel U, Rocken C, Nepple K, Wolke C, Spiess A, Huth C, Ansorge S, Klein HU, Goette A. Altered expression of ADAMs (A Disintegrin And Metalloproteinase) in fibrillating human atria. Circulation 2002 February 12;105(6):720-5.

(27) Nakano Y, Niida S, Dote K, Takenaka S, Hirao H, Miura F, Ishida M, Shingu T, Sueda T, Yoshizumi M, Chayama K. Matrix metalloproteinase- 9 contributes to human atrial remodeling during atrial fibrillation. J Am Coll Cardiol 2004 March 3;43(5):818-25.

(28) Acampa M, Lazzerini PE, Guideri F, Rechichi S, Capecchi PL, Maccherini M, Laghi-Pasini F. Homocysteine and $\mathrm{P}$ wave dispersion in patients with heart transplantation. Clin Transplant 2011 January;25(1):119-25.

(29) Cai BZ, Gong DM, Liu Y, Pan ZW, Xu CQ, Bai YL, Qiao GF, Lu YJ, Yang BF. Homocysteine inhibits potassium channels in human atrial myocytes. Clin Exp Pharmacol Physiol 2007 September;34(9):851-5.

(30) Cai B, Shan L, Gong D, Pan Z, Ai J, Xu C, Lu Y, Yang B. Homocysteine modulates sodium channel currents in human atrial myocytes. Toxicology 2009 February 27;256(3):201-6.

(31) Gill SS, Pulido OM. Glutamate receptors in peripheral tissues: current knowledge, future research, and implications for toxicology. Toxicol Pathol 2001 March;29(2):208-23. 
(32) Boldyrev AA, Johnson P. Homocysteine and its derivatives as possible modulators of neuronal and non-neuronal cell glutamate receptors in Alzheimer's disease. J Alzheimers Dis 2007 May;11(2):219-28.

(33) Iglesias I, Castillo CA, Leon D, Ruiz MA, Albasanz JL, Martin M. Metabotropic glutamate receptor/phospholipase $\mathrm{C}$ system in female rat heart. Brain Res 2007 June 11;1153:1-11.

(34) Gill SS, Pulido OM, Mueller RW, McGuire PF. Molecular and immunochemical characterization of the ionotropic glutamate receptors in the rat heart. Brain Res Bull 1998 July 15;46(5):429-34.

(35) D'Amico M, Di FC, Rossi F, Rossi F. Arrhythmias induced by myocardial ischaemia-reperfusion are sensitive to ionotropic excitatory amino acid receptor antagonists. Eur J Pharmacol 1999 February 5;366(2-3):167-74.

(36) Nonaka H, Tsujino T, Watari Y, Emoto N, Yokoyama M. Taurine prevents the decrease in expression and secretion of extracellular superoxide dismutase induced by homocysteine: amelioration of homocysteine-induced endoplasmic reticulum stress by taurine. Circulation 2001 September 4;104(10):1165-70.

(37) Tyagi N, Sedoris KC, Steed M, Ovechkin AV, Moshal KS, Tyagi SC. Mechanisms of homocysteine-induced oxidative stress. Am J Physiol Heart Circ Physiol 2005 December;289(6):H2649-H2656.

(38) Welch GN, Upchurch GR, Jr., Farivar RS, Pigazzi A, Vu K, Brecher P, Keaney $\mathrm{JF}$, Jr., Loscalzo J. Homocysteine-induced nitric oxide production in vascular smooth-muscle cells by NF-kappa B-dependent transcriptional activation of Nos2. Proc Assoc Am Physicians 1998 January;1 10(1):22-31.

(39) Moshal KS, Metreveli N, Frank I, Tyagi SC. Mitochondrial MMP activation, dysfunction and arrhythmogenesis in hyperhomocysteinemia. Curr Vasc Pharmacol 2008 April;6(2):84-92.

(40) Tyagi SC, Rodriguez W, Patel AM, Roberts AM, Falcone JC, Passmore JC, Fleming JT, Joshua IG. Hyperhomocysteinemic diabetic cardiomyopathy: oxidative stress, remodeling, and endothelial-myocyte uncoupling. J Cardiovasc Pharmacol Ther 2005 March;10(1):1-10.

(41) Gourdie RG, Severs NJ, Green CR, Rothery S, Germroth P, Thompson RP. The spatial distribution and relative abundance of gap-junctional connexin 40 and connexin43 correlate to functional properties of components of the cardiac atrioventricular conduction system. J Cell Sci 1993 August;105 ( Pt 4):985-91.

(42) Kanter HL, Laing JG, Beau SL, Beyer EC, Saffitz JE. Distinct patterns of connexin expression in canine Purkinje fibers and ventricular muscle. Circ Res 1993 May;72(5):1124-31. 
(43) Davis LM, Kanter HL, Beyer EC, Saffitz JE. Distinct gap junction protein phenotypes in cardiac tissues with disparate conduction properties. J Am Coll Cardiol 1994 October;24(4):1124-32.

(44) Kasi VS, Xiao HD, Shang LL, Iravanian S, Langberg J, Witham EA, Jiao Z, Gallego CJ, Bernstein KE, Dudley SC, Jr. Cardiac-restricted angiotensinconverting enzyme overexpression causes conduction defects and connexin dysregulation. Am J Physiol Heart Circ Physiol 2007 July;293(1):H182-H192.

(45) Betsuyaku T, Nnebe NS, Sundset R, Patibandla S, Krueger CM, Yamada KA. Overexpression of cardiac connexin 45 increases susceptibility to ventricular tachyarrhythmias in vivo. Am J Physiol Heart Circ Physiol 2006 January;290(1):H163-H171.

(46) Hagendorff A, Schumacher B, Kirchhoff S, Luderitz B, Willecke K. Conduction disturbances and increased atrial vulnerability in Connexin40-deficient mice analyzed by transesophageal stimulation. Circulation 1999 March 23;99(11):1508-15.

(47) Alcolea S, Jarry-Guichard T, de BJ, Gonzalez D, Lamers W, Coppen S, Barrio L, Jongsma H, Gros D, van RH. Replacement of connexin 40 by connexin 45 in the mouse: impact on cardiac electrical conduction. Circ Res 2004 January 9;94(1):100-9.

(48) Verheijck EE, van Kempen MJ, Veereschild M, Lurvink J, Jongsma HJ, Bouman LN. Electrophysiological features of the mouse sinoatrial node in relation to connexin distribution. Cardiovasc Res 2001 October;52(1):40-50.

(49) Bukauskas FF, Bukauskiene A, Bennett MV, Verselis VK. Gating properties of gap junction channels assembled from connexin 43 and connexin 43 fused with green fluorescent protein. Biophys $J 2001$ July;81(1):137-52.

(50) Kreuzberg MM, Sohl G, Kim JS, Verselis VK, Willecke K, Bukauskas FF. Functional properties of mouse connexin 30.2 expressed in the conduction system of the heart. Circ Res 2005 June 10;96(11):1169-77.

(51) Bukauskas FF, Elfgang C, Willecke K, Weingart R. Biophysical properties of gap junction channels formed by mouse connexin 40 in induced pairs of transfected human HeLa cells. Biophys $J 1995$ June;68(6):2289-98.

(52) Coppen SR, Dupont E, Rothery S, Severs NJ. Connexin45 expression is preferentially associated with the ventricular conduction system in mouse and rat heart. Circ Res 1998 February 9;82(2):232-43.

(53) Spear JF, Michelson EL, Moore EN. Cellular electrophysiologic characteristics of chronically infarcted myocardium in dogs susceptible to sustained ventricular tachyarrhythmias. J Am Coll Cardiol 1983 April;1(4):1099-110. 
(54) Kreuzberg MM, Schrickel JW, Ghanem A, Kim JS, Degen J, Janssen-Bienhold U, Lewalter T, Tiemann K, Willecke K. Connexin30.2 containing gap junction channels decelerate impulse propagation through the atrioventricular node. Proc Natl Acad Sci U S A 2006 April 11;103(15):5959-64.

(55) Kreuzberg MM, Willecke K, Bukauskas FF. Connexin-mediated cardiac impulse propagation: connexin 30.2 slows atrioventricular conduction in mouse heart. Trends Cardiovasc Med 2006 November;16(8):266-72.

(56) Cottrell GT, Wu Y, Burt JM. Cx40 and Cx43 expression ratio influences heteromeric/ heterotypic gap junction channel properties. Am J Physiol Cell Physiol 2002 June;282(6):C1469-C1482.

(57) Poelzing S, Rosenbaum DS. Altered connexin43 expression produces arrhythmia substrate in heart failure. Am J Physiol Heart Circ Physiol 2004 October;287(4):H1762-H1770.

(58) Ai X, Pogwizd SM. Connexin 43 downregulation and dephosphorylation in nonischemic heart failure is associated with enhanced colocalized protein phosphatase type 2A. Circ Res 2005 January 7;96(1):54-63.

(59) Akar FG, Spragg DD, Tunin RS, Kass DA, Tomaselli GF. Mechanisms underlying conduction slowing and arrhythmogenesis in nonischemic dilated cardiomyopathy. Circ Res 2004 October 1;95(7):717-25.

(60) Peters NS. Myocardial gap junction organization in ischemia and infarction. Microsc Res Tech 1995 August 1;31(5):375-86.

(61) Peters NS, Coromilas J, Severs NJ, Wit AL. Disturbed connexin43 gap junction distribution correlates with the location of reentrant circuits in the epicardial border zone of healing canine infarcts that cause ventricular tachycardia. Circulation 1997 February 18;95(4):988-96.

(62) Matsushita T, Oyamada M, Fujimoto K, Yasuda Y, Masuda S, Wada Y, Oka T, Takamatsu T. Remodeling of cell-cell and cell-extracellular matrix interactions at the border zone of rat myocardial infarcts. Circ Res 1999 November $26 ; 85(11): 1046-55$

(63) Kerwin WF, Botvinick EH, O'Connell JW, Merrick SH, DeMarco T, Chatterjee K, Scheibly K, Saxon LA. Ventricular contraction abnormalities in dilated cardiomyopathy: effect of biventricular pacing to correct interventricular dyssynchrony. J Am Coll Cardiol 2000 April;35(5):1221-7.

(64) Spragg DD, Leclercq C, Loghmani M, Faris OP, Tunin RS, DiSilvestre D, McVeigh ER, Tomaselli GF, Kass DA. Regional alterations in protein expression in the dyssynchronous failing heart. Circulation 2003 August 26;108(8):929-32. 
(65) Gardner PI, Ursell PC, Fenoglio JJ, Jr., Wit AL. Electrophysiologic and anatomic basis for fractionated electrograms recorded from healed myocardial infarcts. Circulation 1985 September;72(3):596-611.

(66) Lerner DL, Yamada KA, Schuessler RB, Saffitz JE. Accelerated onset and increased incidence of ventricular arrhythmias induced by ischemia in $\mathrm{Cx} 43$ deficient mice. Circulation 2000 February 8;101(5):547-52.

(67) Gutstein DE, Morley GE, Vaidya D, Liu F, Chen FL, Stuhlmann H, Fishman GI. Heterogeneous expression of Gap junction channels in the heart leads to conduction defects and ventricular dysfunction. Circulation 2001 September 4;104(10):1194-9.

(68) Gutstein DE, Morley GE, Tamaddon H, Vaidya D, Schneider MD, Chen J, Chien KR, Stuhlmann H, Fishman GI. Conduction slowing and sudden arrhythmic death in mice with cardiac-restricted inactivation of connexin 43 . Circ Res 2001 February 16;88(3):333-9.

(69) Petrich BG, Gong X, Lerner DL, Wang X, Brown JH, Saffitz JE, Wang Y. cJun $\mathrm{N}$-terminal kinase activation mediates downregulation of connexin43 in cardiomyocytes. Circ Res 2002 October 4;91(7):640-7.

(70) Akar FG, Rosenbaum DS. Transmural electrophysiological heterogeneities underlying arrhythmogenesis in heart failure. Circ Res 2003 October 3;93(7):638-45.

(71) Kitamura H, Ohnishi Y, Yoshida A, Okajima K, Azumi H, Ishida A, Galeano EJ, Kubo S, Hayashi Y, Itoh H, Yokoyama M. Heterogeneous loss of connexin 43 protein in nonischemic dilated cardiomyopathy with ventricular tachycardia. J Cardiovasc Electrophysiol 2002 September;13(9):865-70.

(72) Desplantez T, Halliday D, Dupont E, Weingart R. Cardiac connexins Cx43 and Cx45: formation of diverse gap junction channels with diverse electrical properties. Pflugers Arch 2004 July;448(4):363-75.

(73) Martinez AD, Hayrapetyan V, Moreno AP, Beyer EC. Connexin43 and connexin45 form heteromeric gap junction channels in which individual components determine permeability and regulation. Circ Res 2002 May 31;90(10):1100-7.

(74) Rosenberger D, Gargoum R, Tyagi N, Metreveli N, Sen U, Maldonado C, Tyagi $\mathrm{S}$. Homocysteine enriched diet leads to prolonged QT interval and reduced left ventricular performance in telemetric monitored mice. Nutr Metab Cardiovasc Dis 2011 July;21(7):492-8.

(75) Boyett MR, Inada S, Yoo S, Li J, Liu J, Tellez J, Greener ID, Honjo H, Billeter R, Lei M, Zhang H, Efimov IR, Dobrzynski H. Connexins in the sinoatrial and atrioventricular nodes. Adv Cardiol 2006;42:175-97. 
(76) Sanders P, Kistler PM, Morton JB, Spence SJ, Kalman JM. Remodeling of sinus node function in patients with congestive heart failure: reduction in sinus node reserve. Circulation 2004 August 24;110(8):897-903.

(77) Sanders P, Morton JB, Davidson NC, Spence SJ, Vohra JK, Sparks PB, Kalman $\mathrm{JM}$. Electrical remodeling of the atria in congestive heart failure: electrophysiological and electroanatomic mapping in humans. Circulation 2003 September 23;108(12):1461-8.

(78) Maldonado C, Moshal K, Todnem ND, Soni.C.V., Puspakumar SB, Tyagi.S.C. High levels of dietary homocysteine (Hcy) accelerate impulse propagation across the murine atrioventricular node (AVN). FASEB 2008;22(lb58).

(79) MOE GK, PRESTON JB, BURLINGTON H. Physiologic evidence for a dual A-V transmission system. Circ Res 1956 July;4(4):357-75.

(80) Watanabe Y, Hata T. Historical Perspective of Studies on Impulse Formation and Conduction in the AV Node. In: Mazgalev TN, Tchou PJ, eds. Atrial-AV Nodal Electrophysiology: A View from the Millennium. 1 ed. Wiley-Blackwell; 2000. p. 49-59.

(81) Janse MJ, van Capelle FJ, Freud GE, Durrer D. Circus movement within the AV node as a basis for supraventricular tachycardia as shown by multiple microelectrode recording in the isolated rabbit heart. Circ Res 1971 April;28(4):403-14.

(82) Gemel J, Lin X, Collins R, Veenstra RD, Beyer EC. Cx30.2 can form heteromeric gap junction channels with other cardiac connexins. Biochem Biophys Res Commun 2008 May 2;369(2):388-94.

(83) VanderBrink BA, Sellitto C, Saba S, Link MS, Zhu W, Homoud MK, Estes NA, III, Paul DL, Wang PJ. Connexin40-deficient mice exhibit atrioventricular nodal and infra-Hisian conduction abnormalities. J Cardiovasc Electrophysiol 2000 November; 11(11):1270-6.

(84) Denes P, Wu D, Dhingra RC, Chuquimia R, Rosen KM. Demonstration of dual A-V nodal pathways in patients with paroxysmal supraventricular tachycardia. Circulation 1973 September;48(3):549-55.

(85) Zhu W, Saba S, Link MS, Bak E, Homoud MK, Estes NA, III, Paul DL, Wang PJ. Atrioventricular nodal reverse facilitation in connexin40-deficient mice. Heart Rhythm 2005 November;2(11):1231-7.

(86) Bazett HC. An analysis of time relations of electrocardiograms. Heart 1920 January 1;7:353-70.

(87) Mungrue IN, Gros R, You X, Pirani A, Azad A, Csont T, Schulz R, Butany J, Stewart DJ, Husain M. Cardiomyocyte overexpression of iNOS in mice results 
in peroxynitrite generation, heart block, and sudden death. J Clin Invest 2002 March;109(6):735-43.

(88) Moshal KS, Tipparaju SM, Vacek TP, Kumar M, Singh M, Frank IE, Patibandla PK, Tyagi N, Rai J, Metreveli N, Rodriguez WE, Tseng MT, Tyagi SC. Mitochondrial matrix metalloproteinase activation decreases myocyte contractility in hyperhomocysteinemia. Am J Physiol Heart Circ Physiol 2008 August;295(2):H890-H897.

(89) Moshal KS, Kumar M, Tyagi N, Mishra PK, Metreveli N, Rodriguez WE, Tyagi SC. Restoration of contractility in hyperhomocysteinemia by cardiacspecific deletion of NMDA-R1. Am J Physiol Heart Circ Physiol 2009 March;296(3):H887-H892.

(90) Lewis SJ, Barres C, Jacob HJ, Ohta H, Brody MJ. Cardiovascular effects of the $\mathrm{N}$-methyl-D-aspartate receptor antagonist $\mathrm{MK}-801$ in conscious rats. Hypertension 1989 June;13(6 Pt 2):759-65.

(91) Canesin RO, Bonagamba LG, Machado BH. Bradycardic and hypotensive responses to microinjection of L-glutamate into the lateral aspect of the commissural NTS are blocked by an NMDA receptor antagonist. Brain Res 2000 January 3;852(1):68-75.

(92) Haibara AS, Bonagamba LG, Machado BH. Sympathoexcitatory neurotransmission of the chemoreflex in the NTS of awake rats. Am J Physiol 1999 January;276(1 Pt 2):R69-R80.

(93) Stiles MK, Sanders P, Disney P, Brooks A, John B, Lau DH, Shashidhar, Wilson L, Mackenzie L, Young GD. Differential effects of intravenous magnesium on atrioventricular node conduction in supraventricular tachycardia. Am J Cardiol 2007 October 15;100(8):1249-53.

(94) Viskin S, Belhassen B, Sheps D, Laniado S. Clinical and electrophysiologic effects of magnesium sulfate on paroxysmal supraventricular tachycardia and comparison with adenosine triphosphate. Am J Cardiol 1992 October $1 ; 70(9): 879-85$.

(95) Meloni BP, Zhu H, Knuckey NW. Is magnesium neuroprotective following global and focal cerebral ischaemia? A review of published studies. Magnes Res 2006 June; 19(2): 123-37.

(96) DiCarlo LA, Jr., Morady F, de Buitleir M, Krol RB, Schurig L, Annesley TM. Effects of magnesium sulfate on cardiac conduction and refractoriness in humans. J Am Coll Cardiol 1986 June;7(6):1356-62.

(97) Rasmussen HS, Thomsen PE. The electrophysiological effects of intravenous magnesium on human sinus node, atrioventricular node, atrium, and ventricle. Clin Cardiol 1989 February;12(2):85-90. 
(98) Kulick DL, Hong R, Ryzen E, Rude RK, Rubin JN, Elkayam U, Rahimtoola $\mathrm{SH}$, Bhandari AK. Electrophysiologic effects of intravenous magnesium in patients with normal conduction systems and no clinical evidence of significant cardiac disease. Am Heart J 1988 February; 1 15(2):367-73.

(99) Keren A, Dorian P, Davy JM, Opie LH. Effects of magnesium on ischemic and reperfusion arrhythmias in the rat heart and electrophysiologic effects of hypermagnesemia in the anesthetized dog. Cardiovasc Drugs Ther 1988 December;2(5):637-45.

(100) Huang CF, Su MJ. Positive inotropic action of NMDA receptor antagonist (+)MK801 in rat heart. J Biomed Sci 1999 November;6(6):387-98.

(101) Winter CR, Baker RC. L-glutamate-induced changes in intracellular calcium oscillation frequency through non-classical glutamate receptor binding in cultured rat myocardial cells. Life Sci 1995;57(21):1925-34.

(102) Doronzo G, Russo I, Del Mese P, Viretto M, Mattiello L, Trovati M, Anfossi G. Role of NMDA receptor in homocysteine-induced activation of MitogenActivated Protein Kinase and Phosphatidyl Inositol 3-Kinase pathways in cultured human vascular smooth muscle cells. Thromb Res 2009 September $17 ; 125(2): e 23-e 32$.

(103) Poddar R, Paul S. Homocysteine-NMDA receptor-mediated activation of extracellular signal-regulated kinase leads to neuronal cell death. $J$ Neurochem 2009 August;110(3): 1095-106.

(104) Tsai GE, Ragan P, Chang R, Chen S, Linnoila VM, Coyle JT. Increased glutamatergic neurotransmission and oxidative stress after alcohol withdrawal. Am J Psychiatry 1998 June;155(6):726-32.

(105) Grant KA, Valverius P, Hudspith M, Tabakoff B. Ethanol withdrawal seizures and the NMDA receptor complex. Eur $J$ Pharmacol 1990 February $13 ; 176(3): 289-96$.

(106) Leung JC, Marphis T, Craver RD, Silverstein DM. Altered NMDA receptor expression in renal toxicity: Protection with a receptor antagonist. Kidney Int 2004 July;66(1):167-76.

(107) Zhang C, Yi F, Xia M, Boini KM, Zhu Q, Laperle LA, Abais JM, Brimson CA, Li PL. NMDA receptor-mediated activation of NADPH oxidase and glomerulosclerosis in hyperhomocysteinemic rats. Antioxid Redox Signal 2010 October 1;13(7):975-86.

(108) Christie LA, Riedel G, Algaidi SA, Whalley LJ, Platt B. Enhanced hippocampal long-term potentiation in rats after chronic exposure to homocysteine. Neurosci Lett 2005 January 10;373(2):119-24. 
(109) Resink A, Villa M, Benke D, Hidaka H, Mohler H, Balazs R. Characterization of agonist-induced down-regulation of NMDA receptors in cerebellar granule cell cultures. J Neurochem 1996 January;66(1):369-77. 


\title{
Curriculum Vitae
}

\author{
Chirag V. Soni, M.S. \\ 2011 Frankfort Avenue \#311 \\ Louisville, KY 40206 \\ (502) 767-3138 \\ cvsoni01@louisville.edu
}

\section{A. Education}

B.A. Biological Sciences Northwestern University, Evanston, IL 9/1995-6/1999

M.S. Physiology and Biophysics University of Louisville, Louisville, KY $8 / 2003-5 / 2005$

\section{B. Employment}

Research Technician, Children's Memorial Hospital, Northwestern University $10 / 1999-8 / 2003$

Research Technologist, Department of Physiology and Biophysics, University of $10 / 2007-8 / 2009$

Louisville

\section{Awards}

1st Prize Winner, Research!Louisville 2004, Medical Student 2nd -4th Year Division Khan M, Grossi FV, Soni CV, Delamere N, Okafor M, Maldonado C. Delivery of exogenous ATP preserves $\mathrm{Na}+\mathrm{K}+$ pump function during chemical hypoxia. 8th Annual Research!Louisville, Louisville, KY. November 3-7, 2004.

\section{$1^{\text {st }}$ Prize Winner, Research!Louisville 2008, Research Staff Division}

Soni C, Todnem ND, Pushpakumar S, Tyagi S, Maldonado C. High levels of dietary homocysteine accelerate impulse propagation across the murine atrioventricular node. $12^{\text {th }}$ Annual Research!Louisville, Louisville, KY, October 20-24, 2008.

$1^{\text {st }}$ Prize Winner, Research!Louisville 2010, Post-Doctoral Fellows Division Pushpakumar SB, Perez-Abadia G, Todnem ND, Soni CV, Fensterer TF, Patibandla P, Barker JH, Maldonado C. Enhancing Complement Control on The Endothelial Barrier Reduces Renal Dysfunction Following Ischemia Reperfusion Injury. $14^{\text {th }}$ Annual Research!Louisville, October 11- 5, 2010, Louisville, KY. 


\section{Presentations}

1. Khan M, Grossi FV, Soni CV, Delamere N, Okafor M, Maldonado C. Delivery of exogenous ATP preserves $\mathrm{Na}+\mathrm{K}+$ pump function during chemical hypoxia. $8^{\text {th }}$ Annual Research!Louisville, Louisville, KY. November 3-7, 2004.

2. Maldonado C, Grossi FV, Khan M, Soni C, Okafor MC, Vasilic D, Ehringer WC, Perez-Abadia G, Delamere NA, Barker JH. Delivery of exogenous ATP maintains sodium-potasium pump activity in endothelial cells during chemical hypoxia. American College of Surgeons, $91^{\text {st }}$ Annual Clinical Congress, San Francisco, CA. October 16-20, 2005.

3. Maldonado C, Moshal K, Todnem N, Soni C, Tyagi SC. High levels of dietary homocysteine (Hcy) accelerate impulse propagation across the murine atrioventricular node (AVN). Presented at Federation of American Societies for Experimental Biology, San Diego, CA, April 4-9, 2008.

4. Soni C, Todnem ND, Pushpakumar S, Tyagi S, Maldonado C. High levels of dietary homocysteine accelerate impulse propagation across the murine atrioventricular node. $12^{\text {th }}$ Annual Research!Louisville, Louisville, KY, October 20-24, 2008.

5. Pushpakumar SB, Perez-Abadia G, Todnem ND, Soni CV, Fensterer TF, Patibandla PK, Barker JH, Maldonado C. Endothelium Targeted AntiComplement Therapy Protects Renal Function Following Ischemia and Reperfusion Injury. Presented at $13^{\text {th }}$ Annual Research!Louisville, Louisville, KY November 2009

6. Fensterer TF, Maldonado C, Perez-Abadia G, Pushpakumar S, Soni CV, Patibandla P, Todnem ND. Department of Physiology.A Novel Cuff Design to Facilitate Vessel Anastomosis for Cervical Heart Transplantation in Rodents. $13^{\text {th }}$ Annual Research!Louisville, Louisville, KY. November 2009

7. Todnem ND, Maldonado C, Soni CV, Givvimani S, Pushpakumar SB, Fernandes TF, Villafane J, Tyagi SC. Elevated Homocysteine in the Blood Increases AV Nodal Conduction: Role of the Cardiac NMDA Receptor. $13^{\text {th }}$ Annual Research!Louisville, Louisville, KY. November 2009.

8. Perez-Abadia G, Goga L, Pushpakumar S, Olson P, Anderson G, Soni CV, Barker $\mathrm{JH}$, Maldonado C. Characterization of a novel liposome based therapy to reduce complement deposition on cell membranes. Presented at Federation of American Societies for Experimental Biology, Anaheim, CA, April 24-28, 2010.

9. Claudio Maldonado, Nathan D. Todnem, Chirag V. Soni, Srikanth Givvimani, Sathnur Pushpakumar, Phani K. Patibandla, Suresh C. Tyagi. Mild hyperhomocysteinemia increases atrioventricular nodal conduction: Role of the 
cardiac NMDA receptor. Presented at Federation of American Societies for Experimental Biology, Anaheim, CA, April 24-28, 2010.

10. Soni CV, Maldonado C, Todnem ND, Givvimani S, Pushpakumar SB, Patibandla P, Villafane J, Tyagi SC. Hyperhomocysteinemia Alters Sinoatrial and Atrioventricular Nodal Function: Role of the Cardiac NMDA Receptor. $14^{\text {th }}$ Annual Research!Louisville, October 11-15, 2010, Louisville, KY.

11. Pushpakumar SB, Perez-Abadia G, Todnem ND, Soni CV, Fensterer TF, Patibandla P, Barker JH, Maldonado C. Enhancing Complement Control on The Endothelial Barrier Reduces Renal Dysfunction Following Ischemia Reperfusion Injury. $14^{\text {th }}$ Annual Research!Louisville, October 11- 5, 2010, Louisville, KY.

12. Fensterer TF, Patibandla P, Perez-Abadia G, David Song, BS, Pushpakumar SB, Soni CV, Claudio Maldonado, PhD. Complement Inactivation in Heart Transplantation. $14^{\text {th }}$ Annual Research!Louisville, October 11-15, 2010, Louisville, KY.

13. Patibandla P, Fensterer TF, Perez-Abadia G, Pushpakumar SB, Soni CV, Harrison A, Maldonado C. Enhancing Complement Control to Protect the Endothelial Cell Injury. $14^{\text {th }}$ Annual Research!Louisville, October 11-15, 2010, Louisville, KY.

\section{E. Publications}

1. Maldonado C, Soni CV, Todnem ND, Pushpakumar S, Rosenberger D, Givvimani S, Villafane J, Tyagi SC. Hyperhomocysteinemia and sudden cardiac death: potential arrhythmogenic mechanisms. Curr Vasc Pharmacol. 2010 Jan;8(1):64-74.

2. Soni CV, Barker JH, Pushpakumar SB, Furr LA, Cunningham M, Banis JC Jr, Frank J. Psychosocial considerations in facial transplantation. Burns. 2010 Nov;36(7):959-64. Epub 2010 Apr 7.

3. Pushpakumar SB, Barker JH, Soni CV, Joseph H, van Aalst VC, Banis JC, Frank J. Clinical considerations in face transplantation. Burns. 2010 Nov;36(7):951-8. Epub 2010 Apr 21.

4. Goga L, Perez-Abadia G, Pushpakumar SB, Cramer D, Yan J, Todnem N, Anderson G, Soni C, Barker J, Maldonado C. Cell membrane modification for rapid display of bi-functional peptides: a novel approach to reduce complement activation. Open Cardiovasc Med J. 2010 Jul 20;4:157-65.

5. Goga L, Pushpakumar SB, Perez-Abadia G, Olson P, Anderson G, Soni CV, Barker JH, Maldonado C. A novel liposome-based therapy to reduce complement- 
mediated injury in revascularized tissues. J Surg Res. 2011 Jan;165(1):e51-7. Epub 2010 Oct 16.

6. Pushpakumar SB, Perez-Abadia G, Soni C, Wan R, Todnem N, Patibandla PK, Fensterer T, Zhang Q, Barker JH, Maldonado C. Enhancing complement control on endothelial barrier reduces renal post-ischemia dysfunction. J Surg Res. 2011 Oct;170(2):e263-70. Epub 2011 Jul 7. 